\title{
Ruthenium(II)-Mediated Carbon-Carbon Bond Formation between Acetonitrile and Pyrrole: Combined Experimental and Computational Study
}

\author{
Karl A. Pittard, ${ }^{\dagger}$ Thomas R. Cundari, ${ }^{\dagger}$ T. Brent Gunnoe,,${ }^{* \dagger}$ Cynthia S. Day, ${ }^{\#}$ and \\ Jeffrey L. Petersen ${ }^{\S}$ \\ Department of Chemistry, North Carolina State University, \\ Raleigh, North Carolina 27695-8204, Department of Chemistry, University of North Texas, \\ Box 305070, Denton, Texas 76203-5070, Department of Chemistry, Wake Forest University, \\ Winston-Salem, North Carolina 27109, and C. Eugene Bennett Department of Chemistry,
} West Virginia University, Morgantown, West Virginia 26506-6045

Received August 2, 2005

\begin{abstract}
The reaction of $\mathrm{TpRu}(\mathrm{CO})(\mathrm{NCMe})(\mathrm{Me})(\mathbf{1})$ and pyrrole forms $\mathrm{TpRu}(\mathrm{CO})\left\{\kappa^{2}-N, N-(\mathrm{H}) \mathrm{N}=\right.$ $\left.\mathrm{C}(\mathrm{Me})\left(\mathrm{NC}_{4} \mathrm{H}_{3}\right)\right\}(\mathbf{2})$. The formation of complex 2 involves the cleavage of the $\mathrm{N}-\mathrm{H}$ bond and 2-position $\mathrm{C}-\mathrm{H}$ bonds of pyrrole as well as a $\mathrm{C}-\mathrm{C}$ bond forming step between pyrrole and the acetonitrile ligand of $\mathbf{1}$. Mechanistic studies indicate that the most likely reaction pathway involves initial metal-mediated $\mathrm{N}-\mathrm{H}$ activation of pyrrole to produce $\mathrm{TpRu}(\mathrm{CO})(\mathrm{N}$-pyrrolyl)$(\mathrm{NCMe})(\mathbf{3})$ followed by $\mathrm{C}-\mathrm{C}$ bond formation and proton transfer. Complex $\mathbf{3}$ has been independently prepared and demonstrated to convert to 2 . Computational studies support the suggested selectivity for initial $\mathrm{N}-\mathrm{H}$ bond cleavage in preference to $\mathrm{C}-\mathrm{H}$ bond activation.
\end{abstract}

\section{Introduction}

Late transition metal-catalyzed reactions for $\mathrm{C}-\mathrm{C}$ bond formation that incorporate aryl halides or triflates (e.g., Suzuki, Heck, Sonogashira, Stille, and related transformations) have evolved as important methodologies for organic synthesis. ${ }^{1-8}$ Related catalytic methods that proceed through cleavage of aromatic $\mathrm{C}-\mathrm{H}$ rather than $\mathrm{C}-\mathrm{X}$ bonds would provide more efficient routes and expand the scope of syntheses available as well as the utility of such transformations for agricultural and pharmaceutical applications (Scheme 1). Several advances in the area of catalytic transformations of aromatic carbon-hydrogen bonds have been recently reported. ${ }^{9-26}$ For example, Periana et al. have reported

* To whom correspondence should be addressed. E-mail: brent_gunnoe@ncsu.edu.

North Carolina State University.

$¥$ University of North Texas.

\# Wake Forest University.

\& West Virginia University.

(1) Diederich, F.; Stang, P. J. Metal-Catalyzed Cross-Coupling Reactions; Wiley-VCH: Weinheim, 1998.

(2) Miyaura, N.; Suzuki, A. Chem. Rev. 1995, 95, 2457-2483.

(3) Miyaura, N. Cross-Coupling Reactions: A Practical Guide; Springer: New York, 2002; Vol. 219.

(4) Negishi, E.-i.; Anastasia, L. Chem. Rev. 2003, 103, 1979-2017.

(5) Hassan, J.; Sévignon, M.; Gozzi, C.; Shulz, E.; Lemaire, M. Chem. Rev. 2002, 102, 1359-1469.

(6) Stille, J. K. Angew. Chem., Int. Ed. Engl. 1986, 25, 508-524.

(7) Beletskaya, I. P.; Cheprakov, A. V. Chem. Rev. 2000, 100, 30093066 .

(8) Heck, R. F. In Organic Reactions; Duaben, W. G., Ed.; John Wiley and Sons: New York, 1982; Vol. 27, pp 345-390.

(9) Goj, L. A.; Gunnoe, T. B. Curr. Org. Chem. 2005, 9, 671-685.

(10) Ritleng, V.; Sirlin, C.; Pfeffer, M. Chem. Rev. 2002, 102, 17311769 .

(11) Dyker, G. Angew. Chem., Int. Ed. 1999, 38, 1698-1712.

(12) Goldberg, K. I.; Goldman, A. S. Activation and Functionalization of $\mathrm{C}-\mathrm{H}$ Bonds; American Chemical Society: Washington, DC, 2004; Vol. 885 .

(13) Kakiuchi, F.; Murai, S. Acc. Chem. Res. 2002, 35, 826-834.
Scheme 1. Catalytic $\mathbf{C}-\mathrm{C}$ Bond Formation Involving Aromatic Substrates through $\mathbf{C}-\mathbf{X}(\mathbf{X}=$ halide or trifluoromethanesulfonate; $\mathbf{Y}=\mathbf{C R}_{2}, \mathbf{O}$, or NR) or $\mathbf{C}-\mathrm{H}$ Bond Activation

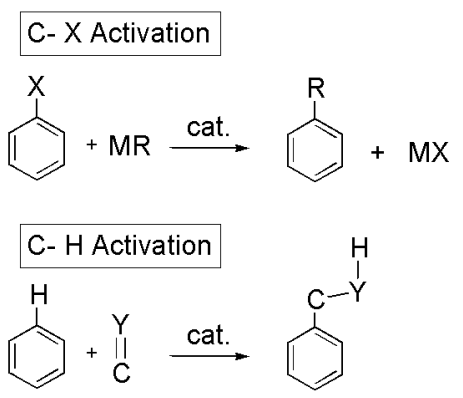

(14) Kakiuchi, F.; Murai, S. In Topics in Organometallic Chemistry; Murai, S., Ed.; Springer: Berlin, 1999; Vol. 3, pp 47-79.

(15) Jia, C.; Kitamura, T.; Fujiwara, Y. Acc. Chem. Res. 2001, 34, 633-639.

(16) Kakiuchi, F.; Chatani, N. Adv. Synth. Catal. 2003, 345, 10771101

(17) Hennessy, E. J.; Buchwald, S. L. J. Am. Chem. Soc. 2003, 125 12084-12085.

(18) Lenges, C. P.; Brookhart, M. J. Am. Chem. Soc. 1999, 121, 6616-6623.

(19) Weissman, H.; Song, X.; Milstein, D. J. Am. Chem. Soc. 2001, $123,337-338$

(20) Thalji, R. K.; Ahrendt, K. A.; Bergman, R. G.; Ellman, J. A. J Am. Chem. Soc. 2001, 123, 9692-9693.

(21) Tan, K. L.; Bergman, R. G.; Ellman, J. A. J. Am. Chem. Soc 2001, 123, 2685-2686.

(22) Sezen, B.; Sames, D. J. Am. Chem. Soc. 2003, 125, 5274-5275.

(23) Jordan, R. F.; Taylor, D. F. J. Am. Chem. Soc. 1989, 111, 778779 .

(24) Cho, J.-Y.; Tse, M. K.; Holmes, D.; Maleczka, R. E.; Smith, M. R., III. Science 2002, 295, 305-308.

(25) Chen, H.; Schlecht, S.; Semple, T. C.; Hartwig, J. F. Science 2000, 287, 1995-1997.

(26) Karshtedt, D.; Bell, A. T.; Tilley, T. D. Organometallics 2004 23, 4169-4171. 
that $\operatorname{Ir}(\mathrm{III})$ complexes catalyze the hydroarylation of olefins with the proposed reaction mechanisms involving metal-mediated $\mathrm{C}-\mathrm{H}$ bond activation. ${ }^{27-31}$ Although primarily limited to olefins or alkynes that possess electron-withdrawing substrates, $\mathrm{Pd}$ and $\mathrm{Au}$ systems have been reported to catalyze the addition of aromatic $\mathrm{C}-\mathrm{H}$ bonds across carbon-carbon multiple bonds. ${ }^{15,32,33}$ Catalytic intramolecular addition of $\mathrm{C}-\mathrm{H}$ bonds across carbon-carbon multiple bonds has also been reported. ${ }^{34-36}$ Recently, Yi et al. have reported the formation of quinoline derivatives through Ru-catalyzed activation of aromatic $\mathrm{C}-\mathrm{H}$ bonds. ${ }^{37}$

Our groups have reported the utilization of $\mathrm{Ru}(\mathrm{II})$ complexes for the catalytic hydroarylation of olefins. ${ }^{38-40}$ For example, $\mathrm{TpRu}(\mathrm{CO})(\mathrm{NCMe})(\mathrm{Ph})(\mathrm{Tp}=$ hydridotris(pyrazolyl)borate) catalyzes the addition of arene $\mathrm{C}-\mathrm{H}$ bonds across the carbon-carbon bonds of ethylene and $\alpha$-olefins, and heteroaryl systems of the type $\mathrm{TpRu}(\mathrm{CO})$ $(\mathrm{NCMe})(\mathrm{Ar})(\mathrm{Ar}=2$-thienyl or 2-furyl) catalyze the regioselective addition of furan or thiophene 2-position $\mathrm{C}-\mathrm{H}$ bonds across the carbon-carbon bond of ethylene. Mechanistic studies of these $\mathrm{Ru}(\mathrm{II})$-catalyzed olefin hydroarylation transformations provide evidence for catalytic cycles that proceed through olefin coordination and insertion into metal-aryl bonds, followed by a metal-mediated $\mathrm{C}-\mathrm{H}$ bond activation to release organic product and reintroduce a metal-aryl bond.$^{39}$

Herein, we report the reaction of $\mathrm{TpRu}(\mathrm{CO})(\mathrm{NCMe})$ (Me) (1) with pyrrole to form a product that contains an $N$-pyrrolyl ligand with a pendant imine group that is coordinated to $\mathrm{Ru}$. The overall reaction involves cleavage of pyrrole $\mathrm{N}-\mathrm{H}$ and $\mathrm{C} 2-\mathrm{H}$ bonds and $\mathrm{C}-\mathrm{C}$ bond formation with the acetonitrile ligand of $\mathbf{1}$. Combined experimental and computational studies reported herein indicate that the transformation likely occurs through initial metal-mediated $\mathrm{N}-\mathrm{H}$ activation.

\section{Results and Discussion}

Experimental Studies: Activation of Pyrrole. Heating the $\mathrm{Ru}(\mathrm{II})$ methyl complex $\mathrm{TpRu}(\mathrm{CO})(\mathrm{NCMe})$ (Me) (1) to $90{ }^{\circ} \mathrm{C}$ in neat pyrrole produces the metallacycle 2 after $2 \mathrm{~h}$ (eq 1). Analysis of the crude reaction mixture by ${ }^{1} \mathrm{H}$ NMR spectroscopy reveals that complex $\mathbf{2}$ is the only observable $\mathrm{TpRu}$ species produced. Com-

(27) Matsumoto, T.; Taube, D. J.; Periana, R. A.; Taube, H.; Yoshida, H. J. Am. Chem. Soc. 2000, 122, 7414-7415.

(28) Matsumoto, T.; Periana, R. A.; Taube, D. J.; Yoshida, H. J. Mol. Catal. A: Chem. 2002, 180, 1-18.

(29) Oxgaard, J.; Muller, R. P.; Goddard, W. A., III; Periana, R. A. J. Am. Chem. Soc. 2004, 126, 352-363.

(30) Oxgaard, J.; Periana, R. A.; Goddard, W. A., III. J. Am. Chem. Soc. 2004, 126, 11658-11665.

(31) Periana, R. A.; Liu, X. Y.; Bhalla, G. Chem. Commun. 2002, 24, 3000-3001.

(32) Shi, Z.; He, C. J. Org. Chem. 2004, 69, 3669-3671.

(33) Yao, X.; Li, C.-J. J. Am. Chem. Soc. 2004, 126, 6884-6885.

(34) Pastine, S. J.; Youn, S. W.; Sames, D. Org. Lett. 2003, 5, 10551058.

(35) Youn, S. W.; Pastine, S. J.; Sames, D. Org. Lett. 2004, 6, 581584.

(36) Pastine, S. J.; Youn, S. W.; Sames, D. Tetrahedron 2003, 59, $8859-8868$

(37) Yi, C. S.; Yun, S. Y.; Guzei, I. A. J. Am. Chem. Soc. 2005, 127, $5782-5783$

(38) Lail, M.; Arrowood, B. N.; Gunnoe, T. B. J. Am. Chem. Soc. 2003, 125, 7506-7507.

(39) Lail, M.; Bell, C. M.; Conner, D.; Cundari, T. R.; Gunnoe, T. B.; Petersen, J. L. Organometallics 2004, 23, 5007-5020.

(40) Pittard, K. A.; Lee, J. P.; Cundari, T. R.; Gunnoe, T. B.; Petersen, J. L. Organometallics 2004, 23, 5514-5523.

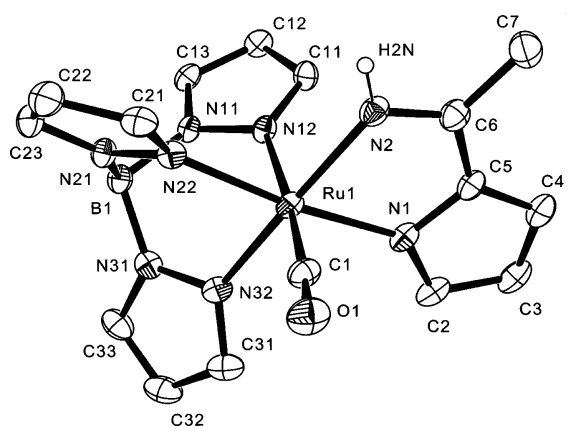

Figure 1. ORTEP of 2 (30\% probability). Selected bond distances $(\AA)$ : Ru1-C1 1.831(3), Ru1-N1 2.073(2), Ru1N2 2.070(2), N1-C5 1.377(3), N1-C2 1.348(3), N2-C6 1.297(3), C5-C6 1.435(4), C4-C5 1.403(4), C2-C3 1.399(4), C3-C4 1.375(4). Selected bond angles (deg): Ru1-N2C6 117.6(2), Ru1-N1-C5 113.8(2), Ru1-N1-C2 139.4(2), N1-C5-C6 116.0(2), N2-C6-C7 123.6(3), N2-C6-C5 115.2(2), Ru1-C1-O1 174.3(2), N2-Ru1-N1 77.44(9), N22-Ru1-N32 87.38(8), N12-Ru1-N22 83.47(7), N32Ru1-N12 86.36(8), N32-Ru1-N2 171.91(8), N22-Ru1N1 172.54(8), N12-Ru1-C1 174.06(9).

Table 1. Selected Crystallographic Data and Collection Parameters for Complexes 2 and 3

\begin{tabular}{lll}
\hline & $\begin{array}{c}\mathrm{TpRu}(\mathrm{CO})\left\{\kappa^{2}-N, N-(\mathrm{H}) \mathrm{N}=\right. \\
\left.\mathrm{C}\left(\mathrm{CH}_{3}\right)\left(\mathrm{NC}_{4} \mathrm{H}_{3}\right)\right\}(\mathbf{2})\end{array}$ & $\begin{array}{c}\mathrm{TpRu}(\mathrm{CO})(N-\text { pyrrolyl })- \\
(\mathrm{NCMe})(\mathbf{3})\end{array}$ \\
\hline empirical & $\mathrm{C}_{16} \mathrm{H}_{17} \mathrm{BN}_{8} \mathrm{ORu}$ & $\mathrm{C}_{16} \mathrm{H}_{17} \mathrm{BN}_{8} \mathrm{ORu}$ \\
formula & & 449.26 \\
fw & 449.26 & monoclinic \\
cryst syst & monoclinic & $P 2_{1} / n$ \\
space group & $P 22_{1} / c$ & $10.413(2)$ \\
$a, \AA$ & $7.8719(6)$ & $12.170(2)$ \\
$b, \AA$ & $17.595(1)$ & $15.495(3)$ \\
$c, \AA$ & $13.497(1)$ & 90 \\
$\alpha$, deg & 90 & $106.195(3)$ \\
$\beta$, deg & $96.007(1)$ & 90 \\
$\gamma$, deg & 90 & $1885.7(6)$ \\
$V, \AA^{3}$ & $1859.1(3)$ & 1.582 \\
$Z$ & 4 & $0.0478,0.0998$ \\
$D_{\text {calcd }}, \mathrm{g} \mathrm{cm}{ }^{-3}$ & 1.605 & \\
$\mathrm{R} 1, \mathrm{wR2}$ & $0.0404,0.0842$ & 1.022 \\
$(I>2 \sigma(I))$ & &
\end{tabular}

plex 2 is isolated in $45 \%$ yield after workup and is characterized by $v_{\mathrm{CO}}=1948 \mathrm{~cm}^{-1}$ (IR spectroscopy) as well as resonances due to three pyrrolyl hydrogen atoms $(6.82,6.77$, and $6.09 \mathrm{ppm})$ and a broad singlet due to the $\mathrm{Ru}$-coordinated imine $\mathrm{NH}$ group at $8.45 \mathrm{ppm}$ in the ${ }^{1} \mathrm{H}$ NMR spectrum. Furthermore, a single-crystal X-ray diffraction study has confirmed the identity of 2 (Figure 1 and Table 1). The structure reveals a five-membered metallacycle that incorporates the former pyrrole and acetonitrile substrates. The Ru1-N2 bond distance of the imine group is statistically identical to the Ru1$\mathrm{N} 1$ bond distance to the $N$-pyrrolyl moiety $(2.070(2)$ versus $2.073(2) \AA$ ). A closely related $\mathrm{CpRu}$ (II) $(\mathrm{Cp}=$ cyclopentadienyl) complex has a $\mathrm{Ru}-\mathrm{N}_{\text {pyrrolyl }}$ bond distance of 2.056(11) $\AA$ and a $\mathrm{Ru}-\mathrm{N}_{\text {imine }}$ bond distance of 2.127(11) $\AA$, while an analogous $\left(\eta^{6}-\mathrm{C}_{6} \mathrm{H}_{6}\right) \mathrm{Ru}(\mathrm{II})$ system has $\mathrm{Ru}-\mathrm{N}_{\text {pyrrolyl }}$ and $\mathrm{Ru}-\mathrm{N}_{\text {imine }}$ bond distances of 2.037(6) and 2.101(5) $\AA$, respectively. ${ }^{41,42}$

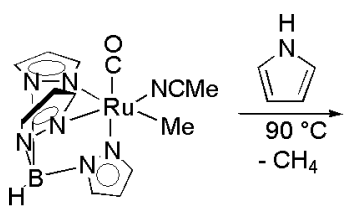

(1)

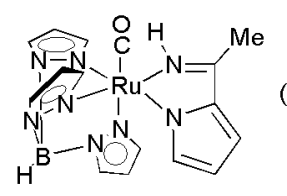

(2) 
Scheme 2. Two Possible Pathways for the Conversion of $\mathrm{TpRu}(\mathrm{CO})(\mathrm{NCMe})(\mathrm{Me})$ (1) and Pyrrole to Complex 2 (complexes in brackets have not been observed)

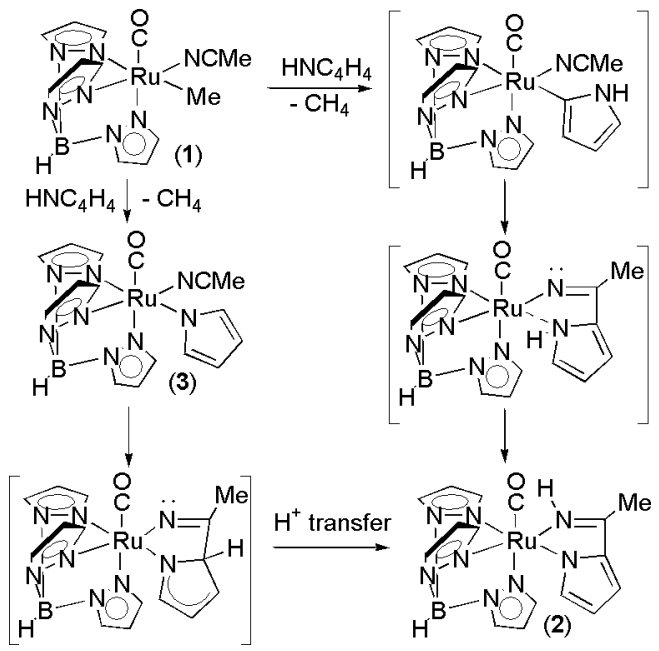

Regardless of the specific mechanism, the production of 2 occurs through $\mathrm{C}-\mathrm{C}$ bond formation between pyrrole and the nitrile ligand of $\mathrm{TpRu}(\mathrm{CO})(\mathrm{NCMe})(\mathrm{Me})$ (1) and is accompanied by release of $\mathrm{CH}_{4}$. Methane production has been detected by NMR spectroscopy in sealed tubes as well as by analysis of the reaction headspace using GC-MS. We have previously demonstrated that complex 1 reacts with benzene, furan, or thiophene to produce methane and $\mathrm{TpRu}(\mathrm{CO})(\mathrm{NCMe})$ $(\mathrm{Ph}), \mathrm{TpRu}(\mathrm{CO})(\mathrm{NCMe})(2$-furyl $)$, or $\mathrm{TpRu}(\mathrm{CO})(\mathrm{NCMe})$ (2-thienyl), respectively, and these reactions likely occur through metal-mediated $\mathrm{C}-\mathrm{H}$ activation. ${ }^{38-40}$ For the transformation of $\mathbf{1}$ and pyrrole to produce complex $\mathbf{2}$, we have considered two possible reaction pathways that are differentiated by initial metal-mediated $\mathrm{C}-\mathrm{H}$ versus $\mathrm{N}-\mathrm{H}$ activation (Scheme 2). In the pathway shown on the left of Scheme 2, initial $\mathrm{N}-\mathrm{H}$ activation of pyrrole produces methane and the $N$-pyrrolyl complex of ruthenium, TpRu(CO)(NCMe)( $N$-pyrrolyl) (3). Subsequent intramolecular $\mathrm{C}-\mathrm{C}$ bond formation followed by proton transfer would produce complex $\mathbf{2}$. Alternatively, initial $\mathrm{C}-\mathrm{H}$ bond activation at the 2-position of pyrrole would produce the 2-pyrrolyl complex $\mathrm{TpRu}(\mathrm{CO})(\mathrm{NCMe})(2$ pyrrolyl) (depicted on the right side of Scheme 2). For the latter reaction pathway, insertion of the acetonitrile ligand into the $\mathrm{Ru}-2$-pyrrolyl bond followed by proton transfer would complete the formation of complex 2.

We attempted to use isotopic labeling of pyrrole to probe the likely reaction pathway. In a control experiment, the reaction of $\mathrm{TpRu}(\mathrm{CO})(\mathrm{NCMe})(\mathrm{Me})$ (1) with pyrrole- $d_{5}$ leads to the production of $\mathrm{CH}_{3} \mathrm{D}$, confirmed through analysis of the reaction headspace using GCMS (eq 2). In addition, the ${ }^{1} \mathrm{H}$ NMR spectrum of the product from this reaction revealed deuterium incorporation into the $N$-pyrrolyl ligand (Figure 2) and at the imine position to produce $\mathbf{2}-d_{4}$. The treatment of $\mathbf{2}-d_{4}$ with $\mathrm{H}_{2} \mathrm{O}$ at $70{ }^{\circ} \mathrm{C}$ results in $\mathrm{H} / \mathrm{D}$ exchange to produce complex 2- $d_{3}$ with hydrogen incorporated at the imine position, as determined by ${ }^{1} \mathrm{H}$ NMR spectroscopy. This

(41) Brunner, H.; Neuhierl, T.; Nuber, B. J. Organomet. Chem. 1998 , $563,173-178$.

(42) Brunner, H.; Oeschey, R.; Nuber, B. Organometallics 1996, 15 , 3616-3624
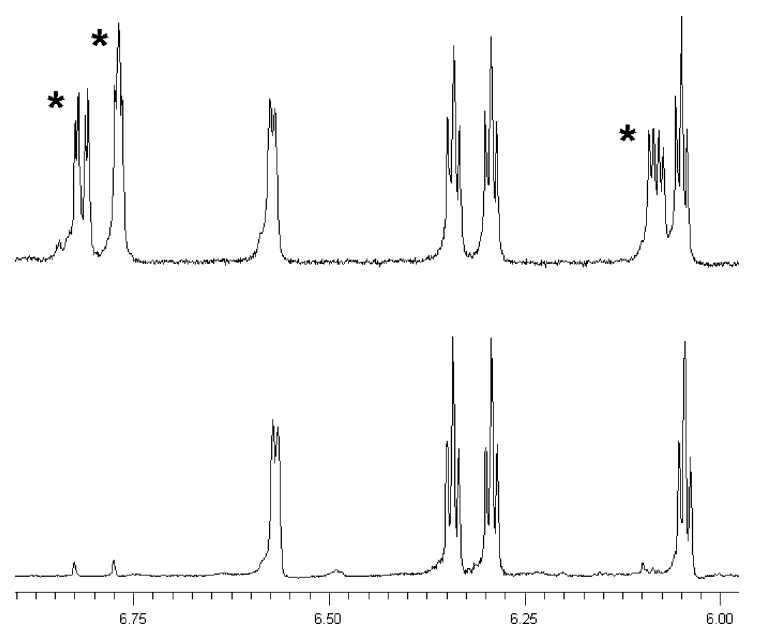

Figure 2. (Top) ${ }^{1} \mathrm{H}$ NMR spectrum of complex 2 in the aromatic region that includes resonances due to the $N$ pyrrolyl ligand (resonances due to $N$-pyrrolyl ligand are labeled with $\left.{ }^{*}\right)$. (Bottom) ${ }^{1} \mathrm{H}$ NMR spectrum of complex 2- $d_{4}$, produced by reaction of $\mathbf{1}$ with pyrrole- $d_{5}$, that demonstrates a decrease in intensity for the resonances due to the $N$-pyrrolyl ligand.

process is reversible, as indicated by the disappearance of the resonance due to the imine hydrogen $\left({ }^{1} \mathrm{H}\right.$ NMR spectroscopy) upon heating 2- $d_{3}$ in $\mathrm{CD}_{3} \mathrm{CN}$ with added $\mathrm{D}_{2} \mathrm{O}($ eq 3$)$.

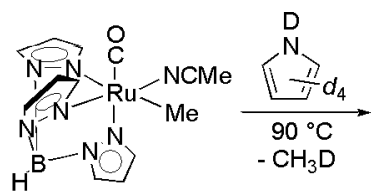

(1)

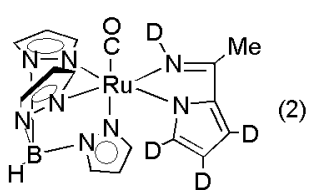

$\left(2-d_{4}\right)$

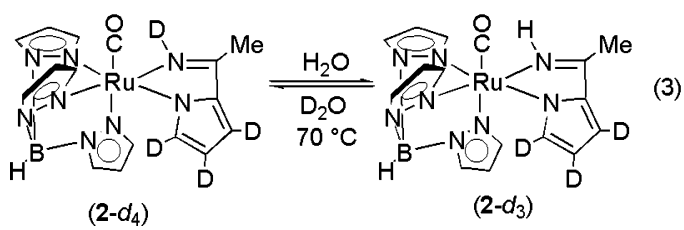

In contrast to the reaction with pyrrole- $d_{5}$, the reaction of $\mathrm{TpRu}(\mathrm{CO})(\mathrm{NCMe})(\mathrm{Me})(\mathbf{1})$ with $N$ - $d_{1}$-pyrrole $\left(\mathrm{DNC}_{4} \mathrm{H}_{4},>90 \%\right.$ deuterium incorporation) results in the production of complex 2 and $\mathrm{CH}_{4}$ without observation of substantial quantities of $\mathrm{CH}_{3} \mathrm{D}$ (eq 4). This result is

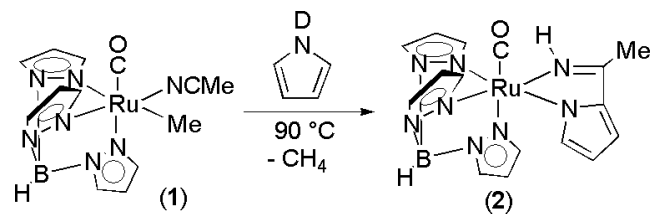

consistent with a reaction mechanism that involves initial metal-mediated $\mathrm{C}-\mathrm{H}$ bond activation at the 2 -position of pyrrole to produce an intermediate $\mathrm{Ru}(\mathrm{II})$ 2-pyrrolyl complex; however, GC-MS of the $N-d_{1}$-pyrrole solution before and after reaction indicates at least $30 \%$ $\mathrm{H} / \mathrm{D}$ scrambling occurs during the course of the reaction. In addition, ${ }^{1} \mathrm{H}$ NMR spectroscopy of the reaction products indicates the incorporation of hydrogen at the imine position, and this observation is inconsistent with initial metal-mediated $\mathrm{C}-\mathrm{H}$ activation at the 2-position of pyrrole (determination of the extent of $\mathrm{H}$ incorpora- 


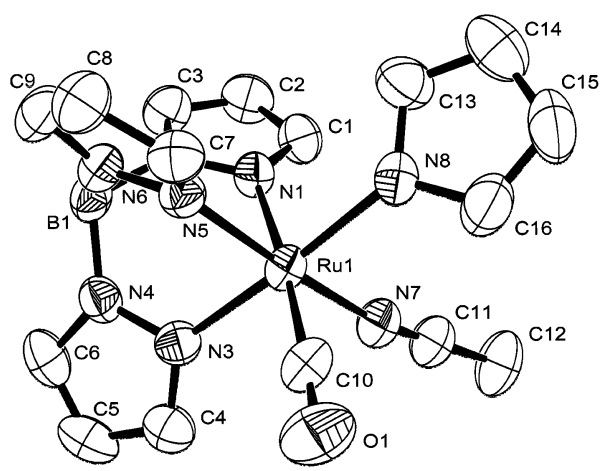

Figure 3. ORTEP of 3 (30\% probability). Selected bond distances (̊): Ru1-N8 2.083(4), N8-C16 1.357(7), N8C13 1.361(7), C13-C14 1.364(8), C14-C15 1.379(8), C15C16 1.362(8), Ru1-C10 1.836(6), C10-O1 1.140(6), Ru1N7 2.038(4), N7-C11 1.127(6). Selected bond angles (deg): C10-Ru1-N8 94.5(2), N7-Ru1-N8 86.58(15), N5Ru1-N8 91.82(15), N8-Ru1-N1 90.57(15), C16-N8-Ru1 127.5(4), C16-N8-C13 104.4(5), C13-N8-Ru1 127.2(4).

tion is complicated by line broadening due to the quadrupolar $\mathrm{N}$ ). Thus, due to isotopic scrambling, reliable conclusions about the mechanism are impossible based on these experiments.

The triflate complex $\mathrm{TpRu}(\mathrm{CO})(\mathrm{NCMe})(\mathrm{OTf})(\mathbf{4})(\mathrm{OTf}$ $=$ trifluoromethanesulfonate) is prepared upon reaction of the previously reported complex $\mathrm{TpRu}(\mathrm{CO})(\mathrm{NCMe})$ (Cl) with $\mathrm{AgOTf},{ }^{43}$ and the reaction of 4 with $\mathrm{LiNC}_{4} \mathrm{H}_{4}$ produces $\mathrm{TpRu}(\mathrm{CO})(N$-pyrrolyl)(NCMe) (3) (eq 5$)$. The

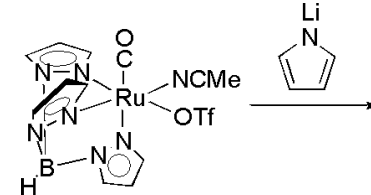

(4)

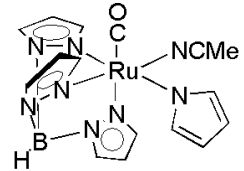

(3)
$N$-pyrrolyl complex 3 has been characterized by IR ( $\nu_{\mathrm{CO}}$ $\left.=1961 \mathrm{~cm}^{-1}\right),{ }^{1} \mathrm{H}$ and ${ }^{13} \mathrm{C}$ NMR spectroscopy, and a single-crystal X-ray diffraction study. ${ }^{1} \mathrm{H}$ NMR spectroscopy reveals multiplets integrating for $2 \mathrm{H}$ each at 6.36 and $6.16 \mathrm{ppm}$ due to the 2- and 3-position hydrogen atoms of the $N$-pyrrolyl ligand, respectively. Additional evidence of the identity of $\mathbf{3}$ is derived from its reaction with $\mathrm{HCl}$ at $-78{ }^{\circ} \mathrm{C}$ to produce free pyrrole and the previously reported complex $\mathrm{TpRu}(\mathrm{CO})(\mathrm{NCMe})(\mathrm{Cl})(\mathrm{eq}$ 6). ${ }^{39}$ An X-ray diffraction study of a single crystal of $\mathbf{3}$

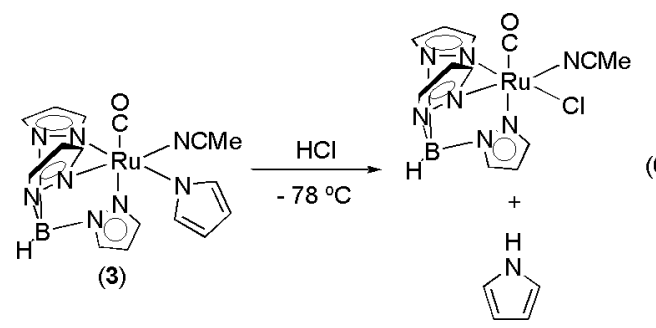

reveals its structure as a monomeric $\mathrm{Ru}$ (II) $\mathrm{N}$-pyrrolyl complex (Table 1 and Figure 3). The $\mathrm{Ru}-\mathrm{N}_{\text {pyrrolyl }}$ bond distance of 2.083(4) $\AA$ is shorter than the corresponding bond distance $(2.153(6) \AA)$ of $\mathrm{Ru}\left(1,5-\eta^{5}-\mathrm{C}_{8} \mathrm{H}_{11}\right)(N$-pyrrolyl) $\left(\mathrm{PEt}_{3}\right)_{2}{ }^{44}$

(43) Lail, M.; Gunnoe, T. B.; Barakat, K. A.; Cundari, T. R. Organometallics 2005, 24, 1301-1305.

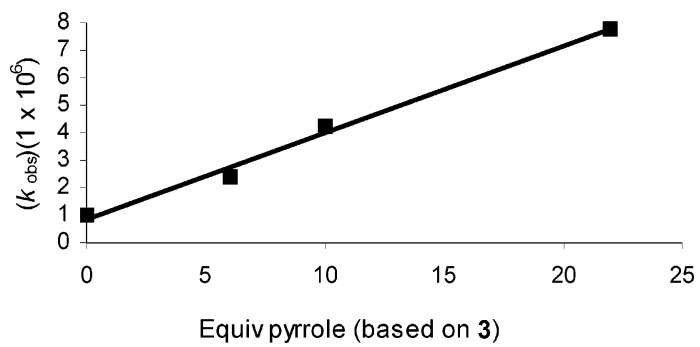

Figure 4. Plot of $k_{\text {obs }}$ versus equivalents of pyrrole (based on $\mathbf{3})$ for the conversion of complex $\mathbf{3}$ to complex $\mathbf{2}$. Reactions were monitored in $\mathrm{CD}_{3} \mathrm{CN}$ at $90{ }^{\circ} \mathrm{C}$.

Reports of 2-pyrrolyl complexes are rare ${ }^{45,46}$ and efforts to produce the 2-pyrrolyl complex $\mathrm{TpRu}(\mathrm{CO})$ (NCMe)(2-pyrrolyl) did not yield clean, isolable products. For example, heating solutions of $\mathrm{TpRu}(\mathrm{CO})(\mathrm{NCMe})(\mathrm{Cl})$ or $\mathrm{TpRu}(\mathrm{CO})(\mathrm{NCMe})(\mathrm{OTf})(4)$ with $\mathrm{Hg}(2$-pyrrolyl)Cl did not yield new products. Considering the possibility that the coordinating ability of chloride or OTf might be problematic, we converted 4 to $[\mathrm{TpRu}(\mathrm{CO})(\mathrm{NCMe})-$ $(\mathrm{THF})]\left[\mathrm{BAr}_{4}{ }_{4}\right](\mathbf{5})$ upon reaction with $\mathrm{NaBAr}_{4}{ }_{4}\left(\mathrm{Ar}^{\prime}=2,6\right.$ $\left(\mathrm{CF}_{3}\right)_{2} \mathrm{C}_{6} \mathrm{H}_{3}$ ) in THF (eq 7); however, the reaction of complex 5 with $\mathrm{Hg}(2$-pyrrolyl)Cl under various conditions did not yield clean and isolable products (complex 3 was not observed in these reactions).

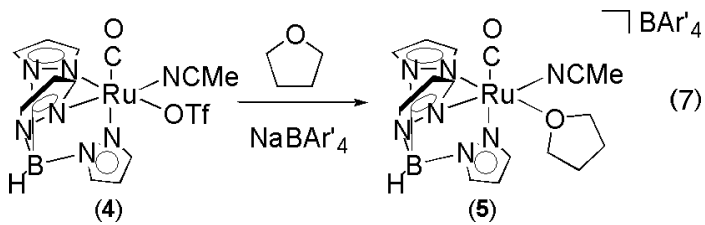

$\mathrm{TpRu}(\mathrm{CO})(N$-pyrrolyl)(NCMe) $(3)$ is the species that would result from metal-mediated $\mathrm{N}-\mathrm{H}$ activation of pyrrole by complex 1 (see the left side of Scheme 2). Thus, if the formation of $\mathbf{2}$ from the reaction of $\mathbf{1}$ and pyrrole proceeded through initial metal-mediated $\mathrm{N}-\mathrm{H}$ activation, it is anticipated that upon heating to $90{ }^{\circ} \mathrm{C}$ complex 3 should convert to complex 2. Heating 3 (90 ${ }^{\circ} \mathrm{C}$ ) in neat $\mathrm{CD}_{3} \mathrm{CN}$ does indeed result in the formation of $\mathbf{2}$, with the rate of the transformation of $\mathbf{3}$ to $\mathbf{2}$ increasing upon addition of pyrrole. For example, a plot of $k_{\text {obs }}$ versus equivalents of pyrrole (based on 3) using $0,6,10$, and 22 equiv of pyrrole reveals a linear relationship (Figure 4). The kinetic experiments were performed at $90{ }^{\circ} \mathrm{C}$ in $\mathrm{CD}_{3} \mathrm{CN}$. These data suggest that free pyrrole potentially serves as a catalyst for the transformation of $\mathbf{3}$ to $\mathbf{2}$. Suspecting that free pyrrole may function as a base to promote proton transfer from the 2-position $\mathrm{C}-\mathrm{H}$ bond of the $N$-pyrrolyl ligand to the acetonitrile nitrogen, we studied the effect of adding the noncoordinating base 2,6-lutidine. In the absence of 2,6lutidine, the conversion of 3 to $2\left(90{ }^{\circ} \mathrm{C}\right.$ in $\left.\mathrm{CD}_{3} \mathrm{CN}\right)$ occurs with $k_{\mathrm{obs}}=9.7 \times 10^{-7} \mathrm{~s}^{-1}$, while the addition of 6 equiv of 2,6-lutidine increases $k_{\text {obs }}$ by a factor of approximately $2.5\left(k_{\mathrm{obs}}=2.5 \times 10^{-6} \mathrm{~s}^{-1}\right)$.

(44) Hirano, M.; Onuki, K.; Kimura, Y.; Komiya, S. Inorg. Chim. Acta 2003, 352, 160-170.

(45) Ng, M. M. P.; Roper, W. R.; Wright, L. J. Organometallics 1994, $13,2563-2565$.

(46) Clark, G. R.; Ng, M. M. P.; Roper, W. R.; Wright, L. J. J. Organomet. Chem. 1995, 491, 219-229. 


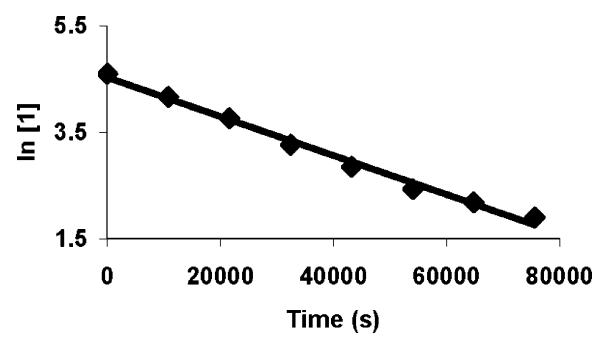

Figure 5. First-order plot $\left(R^{2}=0.99\right)$ for the disappearance of $\mathrm{TpRu}(\mathrm{CO})(\mathrm{NCMe})(\mathrm{Me})(\mathbf{1})$ in the conversion of $\mathbf{1}$ and pyrrole to complex $2\left(75^{\circ} \mathrm{C}\right.$, complex 1 in pyrrole, 0 equiv of $\mathrm{NCMe}$ ).

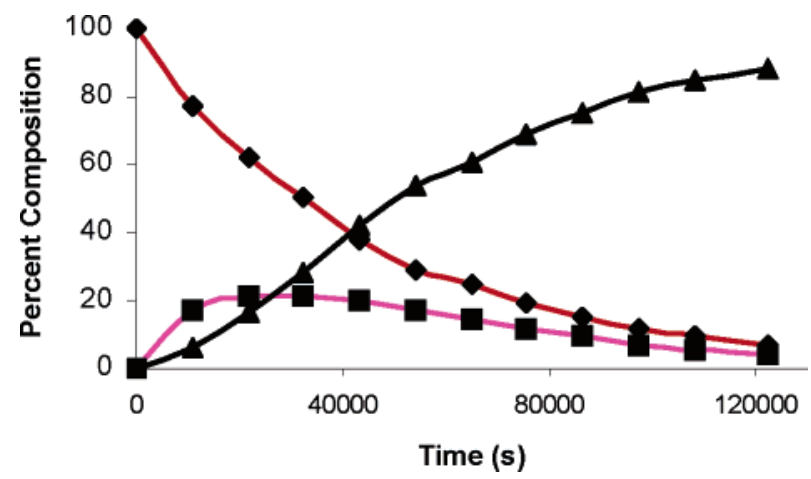

Figure 6. Plot of percent composition of the reaction solution versus time for the conversion of complex $\mathbf{1}$ and pyrrole to complex 2: $\diamond /$ red line $=$ complex $1 ; \boldsymbol{\Delta} /$ black line $=$ complex $2 ; \mathbf{\square} /$ purple line $=$ complex 3 .

We have previously reported that the rate of conversion of complex 1 and benzene to methane and TpRu$(\mathrm{CO})(\mathrm{NCMe})(\mathrm{Ph})$ is suppressed by the presence of free acetonitrile, ${ }^{38}$ and these results have been interpreted to indicate a reaction pathway that involves the formation of the five-coordinate system $\{\mathrm{TpRu}(\mathrm{CO})(\mathrm{Me})\}$, which initiates benzene $\mathrm{C}-\mathrm{H}$ activation. Kinetic experiments were performed to determine if a similar reaction pathway (i.e., metal-mediated $\mathrm{N}-\mathrm{H}$ or $\mathrm{C}-\mathrm{H}$ bond activation by a five-coordinate $\mathrm{Ru}(\mathrm{II})$ system) is likely for the conversion of $\mathbf{1}$ and pyrrole to complex $\mathbf{2}$. These experiments revealed that the addition of acetonitrile does suppress the rate of disappearance of 1 . For example, for the formation of 2 at $75{ }^{\circ} \mathrm{C}$, the rate of disappearance of $\mathbf{1}$ (first-order process, see Figure 5) in the absence of added acetonitrile proceeds with a halflife of approximately $340 \mathrm{~min}\left(k_{\mathrm{obs}}=4.0(8) \times 10^{-5} \mathrm{~s}^{-1}\right)$, while the addition of 30 equiv of acetonitrile increases the half-life to approximately $502 \mathrm{~min}\left(k_{\mathrm{obs}}=2.2(1) \times\right.$ $\left.10^{-5} \mathrm{~s}^{-1}\right)$. Importantly, monitoring the transformation of 1 and pyrrole to 2 by ${ }^{1} H$ NMR spectroscopy reveals that the $N$-pyrrolyl complex 3 is an intermediate in this transformation (Figure 6). Resonances due to $\mathbf{3}$ are clearly observed by ${ }^{1} \mathrm{H}$ NMR spectroscopy during the conversion of $\mathbf{1}$ and pyrrole to complex 2.

Discussion of Pyrrole Bond Activation. Observation of complex $\mathbf{3}$ as an intermediate in the transformation of $\mathbf{1}$ and pyrrole to complex $\mathbf{2}$ suggests that TpRu$(\mathrm{CO})(\mathrm{NCMe})(\mathrm{Me})(\mathbf{1})$ likely initiates $\mathrm{N}-\mathrm{H}$ activation of pyrrole followed by $\mathrm{C}-\mathrm{C}$ bond formation with the acetonitrile ligand; however, it is also possible that metal-mediated $\mathrm{C}-\mathrm{H}$ activation at the 2-position of pyrrole to produce methane and $\mathrm{TpRu}(\mathrm{CO})(\mathrm{NCMe})(2$-pyrrolyl) occurs followed by rapid isomerization of the $\mathrm{Ru}$-2-pyrrolyl complex to the $N$-pyrrolyl complex $\mathbf{3}$. Initial activation of the 2-position $\mathrm{C}-\mathrm{H}$ bond would be consistent with previously reported regioselective $\mathrm{C}-\mathrm{H}$ activation at the 2 -position of furan and thiophene by $\mathrm{TpRu}(\mathrm{CO})(\mathrm{NCMe})$ $(\mathrm{Me}) ; 40$ however, the majority of well-defined examples (i.e., products isolated and fully characterized) of metalmediated activation of pyrrole indicate selectivity for activation of the $\mathrm{N}-\mathrm{H}$ bond in preference to $\mathrm{C}-\mathrm{H}$ bond cleavage. ${ }^{44,47-55} \mathrm{~A}$ possible exception is the reported photolysis of $\left[\mathrm{Cp}_{2} \operatorname{Re}(\mathrm{NCMe})\right]^{+}(\mathrm{Cp}=$ cyclopentadienyl $)$ in pyrrole to produce $\left[\mathrm{Cp}_{2} \operatorname{Re}(2 \text {-pyrrolyl })(\mathrm{H})\right]^{+} .56$

The source of the commonly observed selectivity for the pyrrole $\mathrm{N}-\mathrm{H}$ bond over $\mathrm{C}-\mathrm{H}$ bond activation could be the lower $\mathrm{N}-\mathrm{H}$ bond dissociation enthalpy (BDE) of pyrrole $(\sim 97 \mathrm{kcal} / \mathrm{mol})$ versus the $\mathrm{C}-\mathrm{H}$ BDEs at the 2 -position or 3 -position $(\sim 118 \mathrm{kcal} / \mathrm{mol}) .{ }^{57}$ Thus, transformations that result in bond activation of pyrrole by transition metal centers may be directed to the weaker $\mathrm{N}-\mathrm{H}$ bond; however, control over such transformations could be subtler. For example, it has been demonstrated that oxidative addition reactions of $\mathrm{C}-\mathrm{H}$ bonds by $\mathrm{Rh}$ (I) systems are selective for stronger $\mathrm{C}-\mathrm{H}$ bonds, and such selectivity appears to be kinetic in origin. ${ }^{58,59}$ That is, for alkanes with terminal methyl groups and internal methylene groups, the metal center has access to all $\mathrm{C}-\mathrm{H}$ bonds on the time scale of the $\mathrm{C}-\mathrm{H}$ activation event and breaks the stronger terminal $\mathrm{C}-\mathrm{H}$ bonds more rapidly than the weaker internal $\mathrm{C}-\mathrm{H}$ bonds. Thus, the relative rates of $\mathrm{C}-\mathrm{H}$ bond activation by systems that initiate oxidative addition are potentially controlled to a significant degree by the metal-carbon bond strengths of the incipient products, and the commonly observed selectivity of oxidative addition reactions of pyrrole could be dictated by the combination of weak $\mathrm{N}-\mathrm{H}$ (relative to $\mathrm{C}-\mathrm{H}$ BDEs) and relatively strong $\mathrm{M}-\mathrm{N}_{\text {pyrrolyl }}$ bonds (although $\mathrm{M}-\mathrm{N}_{\text {pyrrolyl }}$ bonds may be weaker than $\mathrm{M}-\mathrm{C}_{\text {pyrrolyl }}$ bonds, the difference in BDE may not make up for the approximately $20 \mathrm{kcal} /$ mol difference in $\mathrm{N}-\mathrm{H}$ versus $\mathrm{C}-\mathrm{H}$ BDEs of pyrrole). ${ }^{60-62}$ Given these considerations, computational studies were

(47) Jones, W. D.; Dong, L.; Myers, A. W. Organometallics 1995 $14,855-861$

(48) Hsu, G. C.; Kosar, W. P.; Jones, W. D. Organometallics 1994, $13,385-396$.

(49) Ladipo, F. T.; Merola, J. S. Inorg. Chem. 1990, 29, 4172-4173.

(50) López, C.; Barón, G.; Arévalo, A.; Muñoz-Hernández, M. A.; García, J. J. J. Organomet. Chem. 2002, 664, 170-175.

(51) Morikita, T.; Hirano, M.; Sasaki, A.; Komiya, S. Inorg. Chim. Acta 1999, 291, 341-354.

(52) Samat, A.; Sala-Pala, J.; Guglielmetti, R.; Guerchais, J. Nouv J. Chem. 1978, 2, 13-14.

(53) Fornies, J.; Green, M.; Spencer, J. L.; Stone, F. G. A. J. Chem Soc., Dalton Trans. 1977, 1006-1009.

(54) Iverson, C. N.; Carter, C. A. G.; Baker, R. T.; Scollard, J. D.; Labinger, J. A.; Bercaw, J. E. J. Am. Chem. Soc. 2003, 125, 1267412675 .

(55) Arndt, S.; Spaniol, T. P.; Okuda, J. Eur. J. Inorg. Chem. 2001 $73-75$

(56) Ogino, H.; Tobita, H.; Endo, K.; Hashidzume, K. Int. J. Photoenergy 1999, 1, 157-160.

(57) Luo, Y.-R. Handbook of Bond Dissociation Energies in Organic Compounds; CRC Press: Boca Raton, 2003.

(58) Northcutt, T. O.; Wick, D. D.; Vetter, A. J.; Jones, W. D. J. Am. Chem. Soc. 2001, 123, 7257-7270.

(59) Flood, T. C.; Janak, K. E.; Iimura, M.; Zhen, H. J. Am. Chem. Soc. 2000, 122, 6783-6784.

(60) Kanzelberger, M.; Zhang, X.; Emge, T. J.; Goldman, A. S.; Zhao, J.; Incarvito, C.; Hartwig, J. F. J. Am. Chem. Soc. 2003, 125, 1364413645.

(61) Bryndza, H. E.; Fong, L. K.; Paciello, R. A.; Tam, W.; Bercaw, J. E. J. Am. Chem. Soc. 1987, 109, 1444-1456.

(62) Bryndza, H. E.; Domaille, P. J.; Tam, W.; Fong, L. K.; Paciello, R. A.; Bercaw, J. E. Polyhedron 1988, 7, 1441-1452. 
Scheme 3. Calculated Free Energies (kcal/mol) for the Conversion of (Tab)Ru(CO)(Me)(NCH) (1') to 2' that Proceeds through Initial Cleavage of the N-H Bond

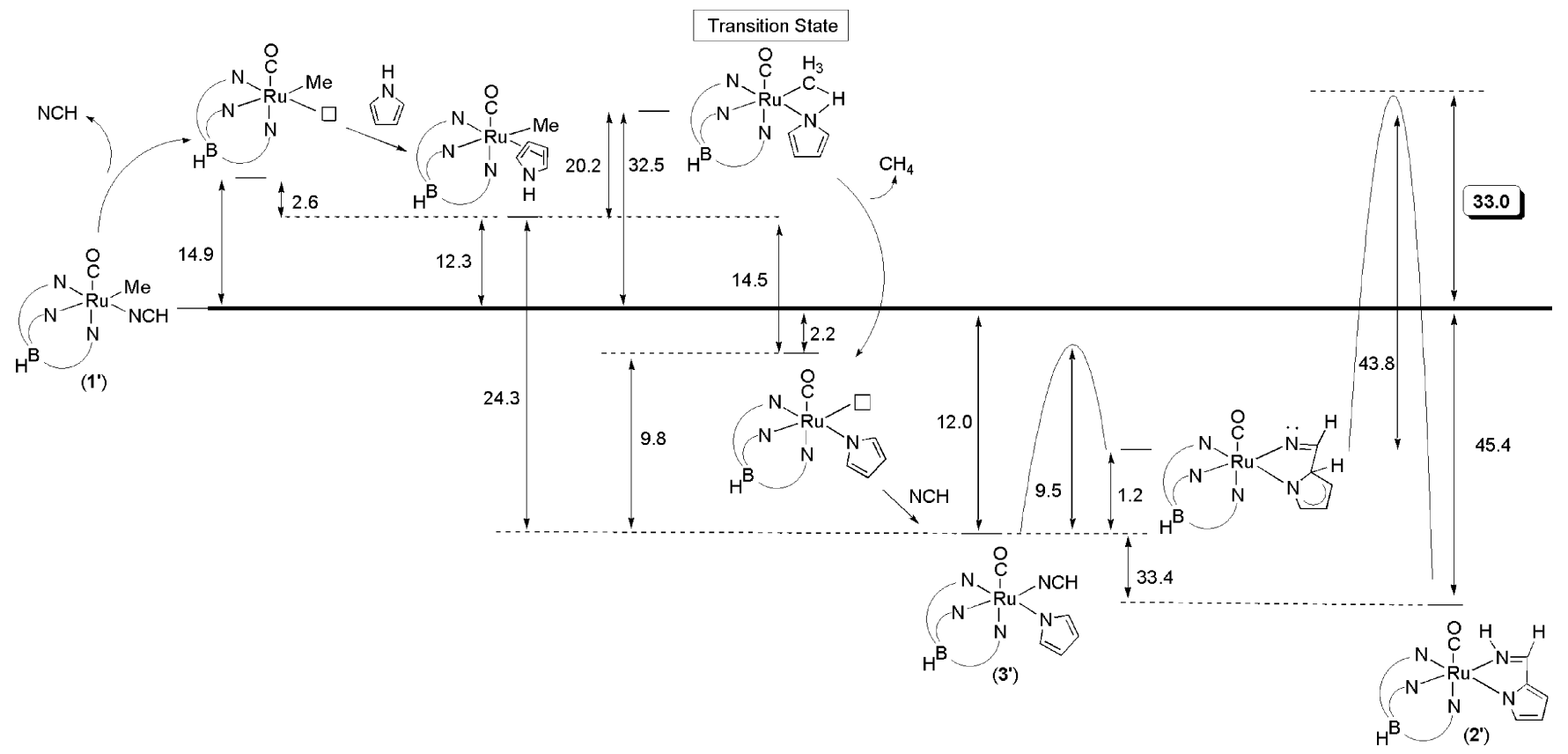

performed to assist our efforts to propose the most reasonable pathway for the formation of $\mathbf{2}$ from complex $\mathbf{1}$ and pyrrole.

Computational Studies: Initial Interaction of (Tab)Ru(CO)(Me)(NCH) and Pyrrole. The "Tab" ligand (tris(azo)borate) and $\mathrm{HCN}$ were used to model $\mathrm{Tp}$ and $\mathrm{MeCN}$, respectively. In previous research, Tab was shown to reproduce the structure and energetics of the full $\mathrm{Tp}$ models for $\mathrm{C}-\mathrm{H}$ activation potential energy surfaces to within $\leq 2 \%$ and approximately 2 $\mathrm{kcal} / \mathrm{mol}$, respectively. ${ }^{63}$ Three modes of interaction between the $\mathrm{Ru}(\mathrm{II})$ complex and pyrrole were investigated. One pathway involves metal-mediated $\mathrm{N}-\mathrm{H}$ activation of pyrrole, while a second pathway proceeds through $\mathrm{C}-\mathrm{H}$ bond activation (see Scheme 2). A third mode of interaction, the potential for nucleophilic addition of free pyrrole to coordinated nitrile, has been studied and disregarded as a likely reaction pathway on the basis of experimental and computational results (see Supporting Information).

Schemes 3 and 4 provide calculated free energies for the conversion of (Tab)Ru(CO)(Me)(NCH) (1') to the cyclometalated product $\mathbf{2}^{\prime}$ for both $\mathrm{N}-\mathrm{H}$ and $\mathrm{C}-\mathrm{H}$ activation pathways, respectively. The binding of the nitrile is calculated to be quite weak with a $\Delta G$ of 14.9 $\mathrm{kcal} / \mathrm{mol}$ for dissociation of $\mathrm{HCN}$ from (Tab)Ru(CO)(Me)(NCH) (1') (Scheme 3). Several different coordination modes of pyrrole to the 16-electron fragment $\{(\mathrm{Tab}) \mathrm{Ru}-$ $(\mathrm{CO})(\mathrm{Me})\}$ were investigated (each with several distinct conformational isomers evaluated) including a dihaptocoordinated $\pi$-complex and ligation through the pyrrole nitrogen. On the basis of the calculations, the most stable (Tab)Ru(CO)(Me)(pyrrole) adduct is the $\pi$-complex $\left(\eta^{2}\right.$-coordinated through the $2,3-\mathrm{C}=\mathrm{C}$ bond). This complex is calculated to be $4.1 \mathrm{kcal} / \mathrm{mol}$ more stable $(\Delta G)$ than the $N$-ligated pyrrole complex. The structure of the

(63) Bergman, R. G.; Cundari, T. R.; Gillespie, A. M.; Gunnoe, T. B.; Harman, W. D.; Klinckman, T. R.; Temple, M. D.; White, D. P. Organometallics 2003, 22, 2331-2337. most stable conformer of ( $\mathrm{Tab}) \mathrm{Ru}(\mathrm{CO})(\mathrm{Me})\left(\eta^{2}\right.$-pyrrole $)$ is shown in Figure 7.

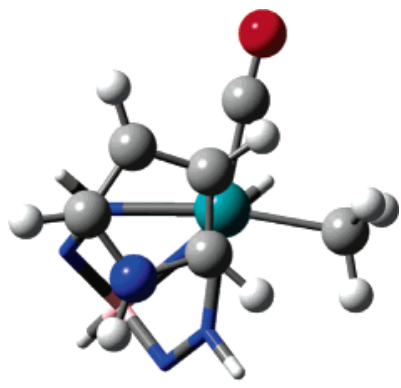

Figure 7. Calculated structure of $(\mathrm{Tab}) \mathrm{Ru}(\mathrm{CO})(\mathrm{Me})\left(\eta^{2}-\right.$ pyrrole). The atoms of the Tab ligand in this and all subsequent figures are shown as colored tubes for clarity.

The binding free energy of pyrrole through its $\pi$-ring in (Tab)Ru(CO)(Me) $\left(\eta^{2}\right.$-pyrrole) is small, only $-2.6 \mathrm{kcal} /$ mol, as expected for coordination to a neutral $\mathrm{d}^{6} \mathrm{ML}_{5}$ fragment. Hence, the exchange of $\mathrm{HCN}$ with pyrrole is calculated to be endergonic by $12.3 \mathrm{kcal} / \mathrm{mol}$. The weak binding of $\eta^{2}$-pyrrole is also evident in the small structural changes that take place in the pyrrole fragment upon ligation to $\{(\mathrm{Tab}) \mathrm{Ru}(\mathrm{CO})(\mathrm{Me})\}$.

Computational Studies: Transition States for $\mathbf{N}-\mathbf{H} / \mathbf{C}-\mathbf{H}$ Bond Activation. In a previous study on $\mathrm{C}-\mathrm{H}$ activation of benzene by $\mathbf{1}^{\prime}$ a variety of transition states were investigated including those derived from oxidative addition and $\sigma$-bond metathesis pathways. ${ }^{39}$ In all cases, transition state searches converged to fourcentered transition states reminiscent of $\sigma$-bond metathesis processes that are the hallmark of $\mathrm{C}-\mathrm{H}$ activation by $\mathrm{d}^{0}$ metal systems. ${ }^{64-67} \mathrm{~A}$ similar transition state was found by Oxgaard and Goddard for the TpRu-

(64) Labinger, J. A.; Bercaw, J. E. Nature 2002, 417, 507-514.

(65) Watson, P. L. In Selective Hydrocarbon Activation: Principles and Progress; Davies, J. A., Watson, P. L., Liebman, J. F., Greenberg, A., Eds.; VCH Publishers: New York, 1990; pp 79-112.

(66) Rothwell, I. P. Polyhedron 1985, 4, 177-200. 
Scheme 4. Calculated Free Energies (kcal/mol) for the Conversion of (Tab)Ru(CO)(Me)(NCH) (1') to 2' that Proceeds through Initial Cleavage of the C2-H Bond

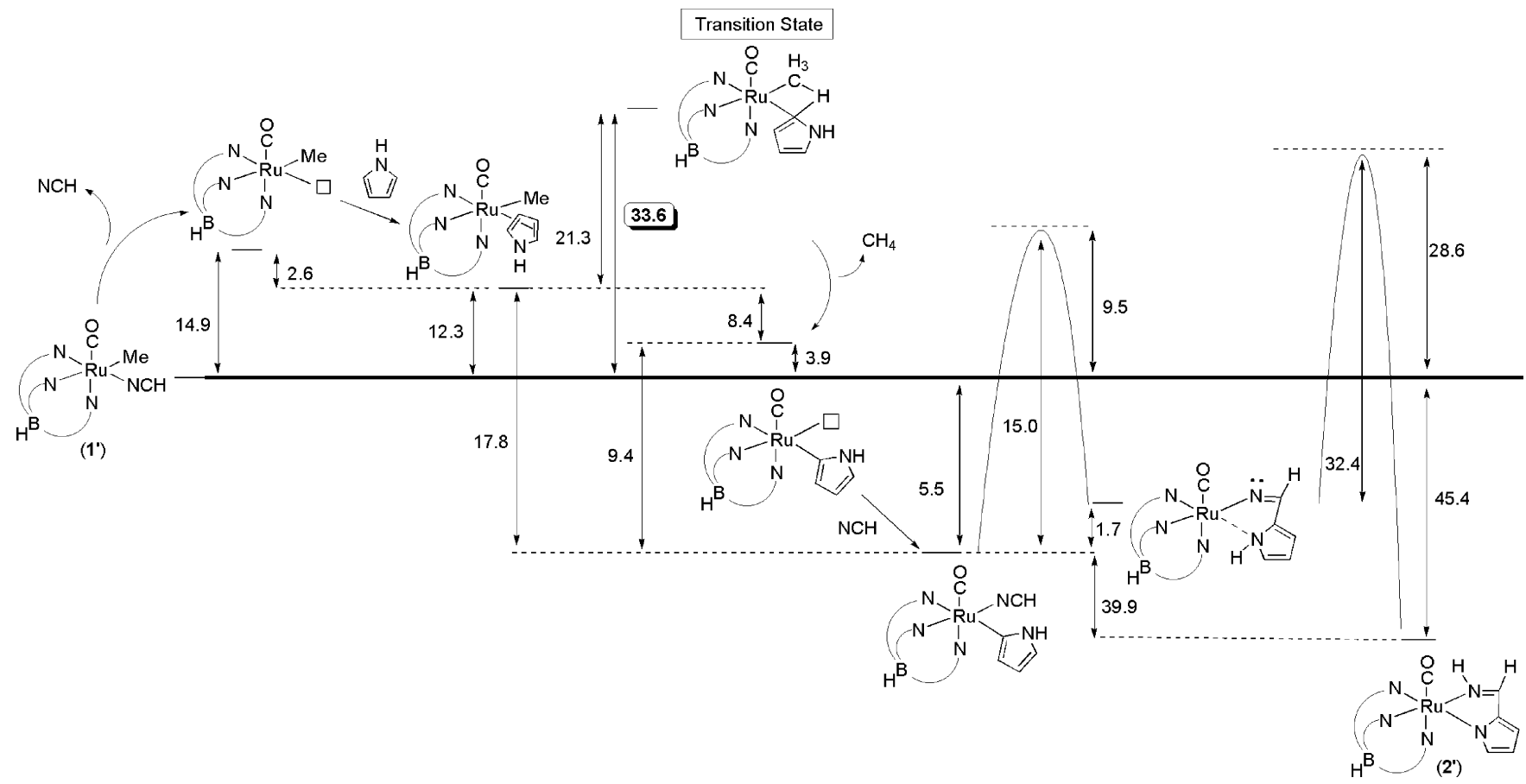

(II) system as well as a related Ir(III) complex, and the term oxidative hydrogen migration was used to label the transition state due to the close contact between the transition metal and the hydrogen atom undergoing transfer. ${ }^{29,68}$

The isomeric transition states for activation of the $\mathrm{C} 2-\mathrm{H}, \mathrm{C} 3-\mathrm{H}$, and $\mathrm{N}-\mathrm{H}$ bonds of pyrrole were compared (Scheme 5). The calculated free energy ordering of the three transition states is (relative energies in parentheses) as follows: $\mathrm{N}-\mathrm{H}(0 \mathrm{kcal} / \mathrm{mol})<\mathrm{C} 2-\mathrm{H}(1.1$ $\mathrm{kcal} / \mathrm{mol})<\mathrm{C} 3-\mathrm{H}(3.0 \mathrm{kcal} / \mathrm{mol})$. The geometries of the two lower energy transition states (i.e., $\mathrm{C} 2-\mathrm{H}$ and $\mathrm{N}-\mathrm{H}$ bond activation) are shown in Figure 8. Calculations with full Tp models yield the same $\Delta \Delta G^{\ddagger}(1.1 \mathrm{kcal} / \mathrm{mol})$ for $\mathrm{C} 2-\mathrm{H}$ and $\mathrm{N}-\mathrm{H}$ activation as seen with the more compact Tab models. An obvious structural difference in the $\mathrm{N}-\mathrm{H}$ and $\mathrm{C} 2-\mathrm{H}$ activation transition states is the distance between the ruthenium and the transannular hydrogen $\left(\mathrm{H}_{\mathrm{t}}\right)$; it is considerably shorter in the $\mathrm{C}-\mathrm{H}$ activation transition state $(\mathrm{Ru}-\mathrm{H}=1.77 \AA)$ compared to the corresponding $\mathrm{N}-\mathrm{H}$ stationary point $\left(\mathrm{Ru}-\mathrm{H}_{\mathrm{t}}=1.90 \AA\right.$ ) $)$. Thus, the calculated transition state for $\mathrm{C} 2-\mathrm{H}$ bond activation might be considered to possess more oxidative character as compared to the transition state for $\mathrm{N}-\mathrm{H}$ bond activation.

Computational Studies: Products of C3-H, C2$\mathbf{H}$, and $\mathbf{N}-\mathbf{H}$ Activation. The product of $\mathrm{N}-\mathrm{H}$ activation of pyrrole by $\{(\mathrm{Tab}) \mathrm{Ru}(\mathrm{CO})(\mathrm{Me})\}$ to release methane, $\{(\mathrm{Tab}) \mathrm{Ru}(\mathrm{CO})(N$-pyrrolyl $)\}$, is calculated to be 6.1 $\mathrm{kcal} / \mathrm{mol}$ more stable than the corresponding 2-pyrrolyl isomer, $\{(\mathrm{Tab}) \mathrm{Ru}(\mathrm{CO})(2$-pyrrolyl) $\}$, which results from $\mathrm{C} 2-\mathrm{H}$ activation and methane production (Scheme 5). The 2-pyrrolyl system is calculated to be another 4.3

(67) Goldman, A. S.; Goldberg, K. I. In Activation and Functionalization of $\mathrm{C}-\mathrm{H}$ Bonds; Goldberg, K. I., Goldman, A. S., Eds.; American Chemical Society: Washington, D.C., 2004; Vol. 885, pp 1-43.

(68) Oxgaard, J.; Goddard, W. A., III. J. Am. Chem. Soc. 2004, 126, $442-443$.
Scheme 5. Calculated Free Energies (kcal/mol) for Activation of Pyrrole at the $\mathrm{N}-\mathrm{H}, \mathrm{C2}-\mathrm{H}$ and C3-H Positions by (Tab)Ru(CO)(NCH)(Me) (1') $\{\mathrm{Ru}$ $=(\mathbf{T a b}) \operatorname{Ru}(\mathbf{C O})\}$

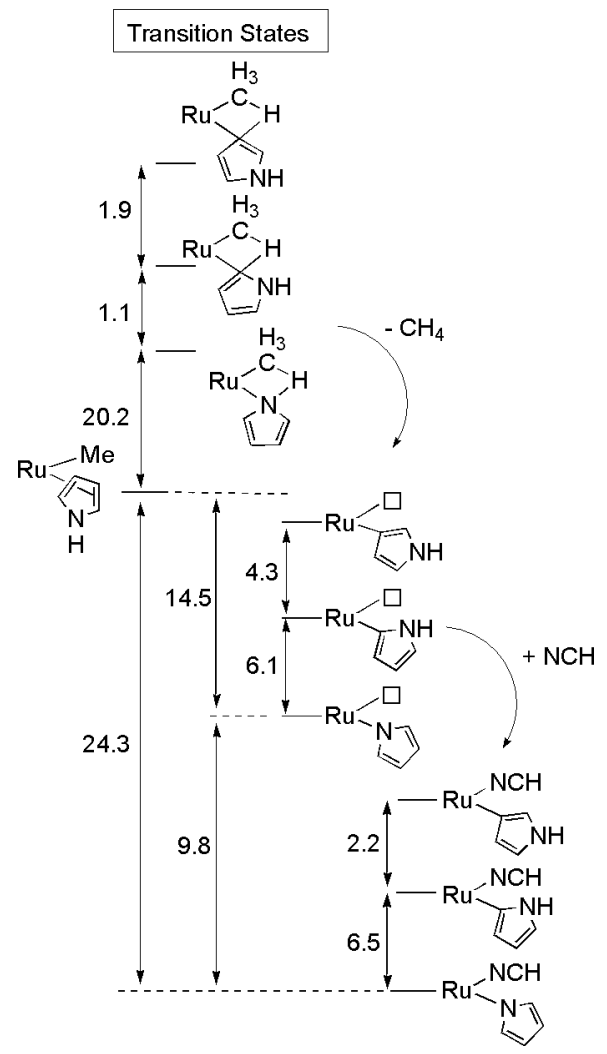

$\mathrm{kcal} / \mathrm{mol}$ more stable than the 3-pyrrolyl isomer, $\{$ (Tab)$\mathrm{Ru}(\mathrm{CO})(3-$ pyrrolyl)\}, which results from $\mathrm{C} 3-\mathrm{H}$ activation. The coordination of $\mathrm{HCN}$ to the various 16 -electron pyrrolyl intermediates yields 18-electron, pseudo-octahedral (Tab)Ru(CO)(NCH)(X-pyrrolyl) $(\mathrm{X}=N, 2$, or 3$)$ systems. The energy ordering for these six-coordinate 


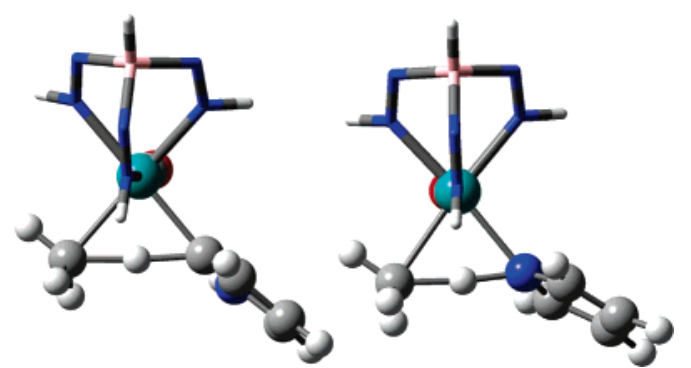

Figure 8. Calculated transition states for $\mathrm{C} 2-\mathrm{H}$ (left) and $\mathrm{N}-\mathrm{H}$ activation (right) of pyrrole by $\{(\mathrm{Tab}) \mathrm{Ru}(\mathrm{CO})(\mathrm{Me})\}$.

species is the same as that seen for the five-coordinate intermediates (relative energies in parentheses): (Tab)$\mathrm{Ru}(\mathrm{CO})(\mathrm{NCH})(N$-pyrrolyl) $(0)<(\mathrm{Tab}) \mathrm{Ru}(\mathrm{CO})(\mathrm{NCH})(2-$ pyrrolyl) $(6.5 \mathrm{kcal} / \mathrm{mol})<(\mathrm{Tab}) \mathrm{Ru}(\mathrm{CO})(\mathrm{NCH})(3$-pyrrolyl $)$ $(8.7 \mathrm{kcal} / \mathrm{mol})$. The calculated energy differences for each set of 16- and 18-electron product isomers are substantial and outside the error limits expected for the computational and chemical models employed when applied to highly similar species. Hence, the thermodynamic preferences for the various pyrrolyl products mimic the kinetic preferences calculated for the isomeric transition states of $\mathrm{N}-\mathrm{H}, \mathrm{C} 2-\mathrm{H}$, and $\mathrm{C} 3-\mathrm{H}$ bond activation with the energetic differences being much more pronounced in the ground states.

Computational Studies: Pathways for CarbonCarbon Bond Formation. The reaction pathway for the production of complex $\mathbf{2}$ upon reaction of $\mathrm{TpRu}(\mathrm{CO})$ $(\mathrm{NCMe})(\mathrm{Me})$ and pyrrole that proceeds through $\mathrm{C}-\mathrm{H}$ bond activation at the 2-position invokes the insertion of acetonitrile into a $\mathrm{Ru}-2$-pyrrolyl bond. This process was also studied computationally, with the results depicted in Scheme 4. The initial insertion step is calculated to be endergonic by $1.7 \mathrm{kcal} / \mathrm{mol}$, with an activation barrier of $15.0 \mathrm{kcal} / \mathrm{mol}$. Subsequent proton transfer produces the $N$-pyrrolyl complex with a chelated imine fragment $\left(\boldsymbol{2}^{\prime}\right)$, with the overall process of insertion and proton transfer calculated to be favorable by $39.9 \mathrm{kcal} / \mathrm{mol}$. The calculated barrier for the final reaction step (i.e., proton transfer) is $32.4 \mathrm{kcal} / \mathrm{mol}$. Thus, according to calculations, the conversion of (Tab)$\mathrm{Ru}(\mathrm{CO})(\mathrm{NCMe})\left(2\right.$-pyrrolyl) to $\mathbf{2}^{\prime}$ is a thermodynamically feasible process with a substantial activation barrier for the proton transfer step in the absence of an external reagent that can assist the proton transfer.

The pathway for formation of metallacycle $\mathbf{2}$ that involves initial $\mathrm{N}-\mathrm{H}$ activation of pyrrole would produce the $N$-pyrrolyl complex 3 followed by $\mathrm{C}-\mathrm{C}$ bond formation and proton transfer. For the model complex (Tab)$\mathrm{Ru}(\mathrm{CO})\left(N\right.$-pyrrolyl)(NCH) $\left(\mathbf{3}^{\prime}\right)$, the initial step, $\mathrm{C}-\mathrm{C}$ bond formation, is calculated to be unfavorable by 1.2 $\mathrm{kcal} / \mathrm{mol}$, with an activation barrier of $9.5 \mathrm{kcal} / \mathrm{mol}$ (Scheme 3). The calculated transition state structure for this reaction step is shown in Figure 9. The $\mathrm{C}-\mathrm{C}$ bond formation starting from complex $\mathbf{3}^{\prime}$ is calculated to have an activation barrier that is $5.5 \mathrm{kcal} / \mathrm{mol}$ less than the $\mathrm{C}-\mathrm{C}$ bond formation step from the $(\mathrm{Tab}) \mathrm{Ru}(\mathrm{CO})(\mathrm{N}-$ CMe)(2-pyrrolyl) system (Schemes 3 and 4). The subsequent proton transfer to form complex $\mathbf{2}^{\prime}$ is calculated to be favorable relative to $\mathbf{3}^{\prime}$ by $33.4 \mathrm{kcal} / \mathrm{mol}$; however, the final reaction step (direct proton transfer between the ligated nitrogen atoms) is calculated to possess a substantial barrier of $43.8 \mathrm{kcal} / \mathrm{mol}$. This calculation is

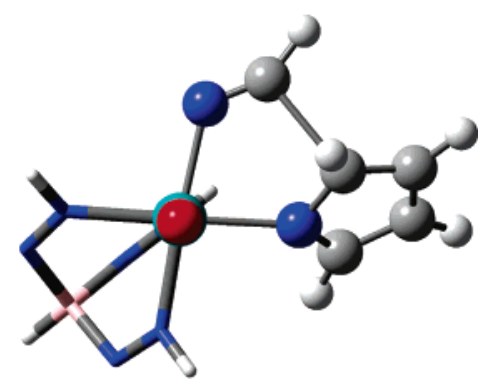

Figure 9. Calculated transition state for $\mathrm{C}-\mathrm{C}$ bond formation from the $N$-pyrrolyl complex $\mathbf{3}^{\prime}$.

consistent with the experimental observation that the conversion of $\mathrm{TpRu}(\mathrm{CO})(\mathrm{NCMe})(N$-pyrrolyl) $(\mathbf{3})$ to complex 2 in neat $\mathrm{CD}_{3} \mathrm{CN}$ or $\mathrm{C}_{6} \mathrm{D}_{6}$ is a slow reaction (see above). For example, the $k_{\text {obs }}$ for the conversion of $\mathbf{3}$ to 2 in $\mathrm{CD}_{3} \mathrm{CN}$ is $9.7 \times 10^{-7} \mathrm{~s}^{-1}$, which yields a $\Delta G^{\ddagger}=31.4$ $\mathrm{kcal} / \mathrm{mol}$ (at $90{ }^{\circ} \mathrm{C}$ ). According to experimental observations, the rate of conversion increases upon addition of base (e.g., pyrrole or 2,6-lutidine) and likely accounts for the more rapid conversion of $\mathbf{1}$ and pyrrole to $\mathbf{2}$ in neat pyrrole. The base provides a catalytic pathway for the transfer of a proton from the 2-position of the pyrrolium intermediate to the azavinylidene nitrogen to yield $\mathbf{2}$.

Summary and Conclusions. Experimental studies provide evidence that the conversion of $\mathbf{1}$ and pyrrole to 2 occurs through initial activation of the $\mathrm{N}-\mathrm{H}$ bond of pyrrole to produce the $N$-pyrrolyl complex 3. Although it is possible that initial $\mathrm{C}-\mathrm{H}$ activation of pyrrole at the 2-position produces $\mathrm{TpRu}(\mathrm{CO})(\mathrm{NCMe})(2$-pyrrolyl) followed by rapid isomerization to the $N$-pyrrolyl complex 3, computational studies indicate that metalmediated $\mathrm{N}-\mathrm{H}$ activation of pyrrole by $\{(\mathrm{Tab}) \mathrm{Ru}(\mathrm{CO})$ $(\mathrm{Me})\}$ is kinetically preferred over $\mathrm{C} 2-\mathrm{H}$ activation by $1.1 \mathrm{kcal} / \mathrm{mol}$. In addition, the formation of (Tab) $\mathrm{Ru}(\mathrm{CO})$ $(\mathrm{NCH})\left(N\right.$-pyrrolyl) $\left(\mathbf{3}^{\prime}\right)$ is calculated to be thermally favored relative to $(\mathrm{Tab}) \mathrm{Ru}(\mathrm{CO})(2$-pyrrolyl $)(\mathrm{NCH})$ by 6.5 $\mathrm{kcal} / \mathrm{mol}$. The same kinetic preference is seen for full Tp models of the respective bond activation transition states. For the formation of $\mathbf{2}^{\prime}$, the calculated free energies for the " $\mathrm{N}-\mathrm{H}$ activation pathway" indicate that the highest energy species lies $33.0 \mathrm{kcal} / \mathrm{mol}$ above $\mathbf{1}^{\prime}$ and corresponds to the transition state for the final proton transfer step. Importantly, experimental results suggest that excess pyrrole increases the rate of this proton transfer step and thus increases the rate of conversion of $\mathbf{3}$ to $\mathbf{2}$. The calculated free energies for the "C2-H activation pathway" indicate that the highest energy species is $33.6 \mathrm{kcal} / \mathrm{mol}$ above $\mathbf{1}^{\prime}$ and corresponds to the $\mathrm{C} 2-\mathrm{H}$ activation step. The combination of experimental and computational results leads us to suggest that the pathway involving initial $\mathrm{N}-\mathrm{H}$ activation (shown on the left side of Scheme 2) is the most likely pathway for the formation of complex $\mathbf{2}$. The observation of this reaction pathway provides the opportunity to explore $\mathrm{C}-\mathrm{C}$ bond formation at the 2-position of pyrrole with other unsaturated substrates that possess $\mathrm{C}-\mathrm{X}(\mathrm{X}$ $=\mathrm{N}$ or $\mathrm{O}$ ) multiple bonds and could ultimately provide a foundation for catalytic $\mathrm{C}-\mathrm{C}$ bond forming reactions of pyrroles. 


\section{Experimental Section}

General Methods. Unless otherwise noted, all synthetic procedures were performed under anaerobic conditions in a nitrogen-filled glovebox or by using standard Schlenk techniques. Glovebox purity was maintained by periodic nitrogen purges and was monitored by an oxygen analyzer $\left(\mathrm{O}_{2}<15\right.$ ppm for all reactions). Diethyl ether was dried by distillation from sodium/benzophenone. Acetonitrile and methanol were dried by distillation from $\mathrm{CaH}_{2}$. Hexanes, methylene chloride, and tetrahydrofuran were purified by passage through a column of activated alumina. Pyrrole was distilled from $\mathrm{Na}_{2-}$ $\mathrm{SO}_{4}$ or $\mathrm{CaH}_{2}$. Acetone- $d_{6}$, benzene- $d_{6}$, acetonitrile- $d_{3}$, and chloroform- $d_{1}$ were degassed with three freeze-pump-thaw cycles and stored under a $\mathrm{N}_{2}$ atmosphere over $4 \AA$ molecular sieves. ${ }^{1} \mathrm{H}$ and ${ }^{13} \mathrm{C}$ NMR spectra were recorded on a Varian Mercury 300 or $400 \mathrm{MHz}$ spectrometer. All ${ }^{1} \mathrm{H}$ and ${ }^{13} \mathrm{C} \mathrm{NMR}$ spectra were referenced against tetramethylsilane using residual proton signals $\left({ }^{1} \mathrm{H} \mathrm{NMR}\right)$ or the ${ }^{13} \mathrm{C}$ resonances of the deuterated solvent $\left({ }^{13} \mathrm{C} \mathrm{NMR}\right) .{ }^{19} \mathrm{~F}$ NMR spectra were obtained on a Varian $300 \mathrm{MHz}$ spectrometer and referenced against an external standard of hexafluorobenzene. Resonances due to the Tp ligand are listed by chemical shift and multiplicity only (all coupling constants for the Tp ligand are $2 \mathrm{~Hz}$ ). IR spectra were acquired using a Mattson Genesis II FT-IR as thin films on $\mathrm{KBr}$ plates or in solution using $\mathrm{KBr}$ solvent cells. GC-MS was performed using a HP GCD system with a $30 \mathrm{~m} \times 0.25$ $\mathrm{mm}$ HP-5 column with $0.25 \mu \mathrm{m}$ film thickness. TpRu(CO)$(\mathrm{NCMe})(\mathrm{Me})(\mathbf{1}), \mathrm{TpRu}(\mathrm{CO})(\mathrm{NCMe})(\mathrm{Cl})$, and $\mathrm{TpRu}(\mathrm{CO})(\mathrm{NC}-$ $\mathrm{Me})(\mathrm{OTf})$ have been previously reported..$^{39,43,69}$ All other reagents were used as purchased from commercial sources.

$\mathbf{T p R u}(\mathrm{CO})\left\{\kappa^{2}-\boldsymbol{N}, \boldsymbol{N}-(\mathbf{H}) \mathbf{N}=\mathbf{C}(\mathbf{M e})\left(\mathbf{N C}_{4} \mathbf{H}_{3}\right)\right\}(\mathbf{2})$. Method A: $\mathrm{TpRu}(\mathrm{CO})(\mathrm{NCMe})(\mathrm{Me})(\mathbf{1})(0.099 \mathrm{~g}, 0.25 \mathrm{mmol})$ was dissolved in approximately $5 \mathrm{~mL}$ of pyrrole. The reaction mixture was removed from the glovebox and placed in an oil bath at $90{ }^{\circ} \mathrm{C}$ for $12 \mathrm{~h}$. After cooling the solution to room temperature, the volatiles were removed in vacuo. Analysis of the reaction mixture by ${ }^{1} \mathrm{H}$ NMR spectroscopy revealed the presence of a single TpRu complex. The yellow oil was taken up in methylene chloride $(\sim 5 \mathrm{~mL})$ and passed through a column of silica gel. After the column was washed with approximately $50 \mathrm{~mL}$ of methylene chloride, the eluent was reduced to dryness under vacuum, leaving an off-white solid. The solid was dissolved in methylene chloride $(\sim 2 \mathrm{~mL})$ and precipitated upon addition of hexanes $(\sim 25 \mathrm{~mL})$. The resulting amorphous solid was collected by vacuum filtration and washed with hexanes. The solid was dried in vacuo to yield an off-white product $(0.051$ g, 45\%). Method B: A screw cap NMR tube was charged with $\mathrm{TpRu}(\mathrm{CO})(N$-pyrrolyl)(NCMe) $(3)(0.017 \mathrm{~g}, 0.038 \mathrm{mmol})$ in 0.6 $\mathrm{mL}$ of acetonitrile- $d_{3}$. The reaction tube was placed in a temperature-regulated oil bath at $90{ }^{\circ} \mathrm{C}$. The conversion of complex 3 to complex 2 under these conditions (as monitored by ${ }^{1} \mathrm{H} \mathrm{NMR}$ ) required several days. IR $(\mathrm{KBr}): v_{\mathrm{CO}}=1948 \mathrm{~cm}^{-1}$, $\nu_{\mathrm{BH}}=2489 \mathrm{~cm}^{-1} .{ }^{1} \mathrm{H}$ NMR (acetone- $\left.d_{6}, \delta\right): 8.45(1 \mathrm{H}, \mathrm{s}$, imine $\mathrm{NH}), 7.97,7.75,6.58$ (each $1 \mathrm{H}$, each a d, Tp $\mathrm{CH} 3$ or 5 position), $7.87(3 \mathrm{H}, \mathrm{m}$, overlapping $\mathrm{Tp} \mathrm{CH} 3$ and 5 position), $6.82(1 \mathrm{H}$, $\mathrm{dd}, J_{\mathrm{HH}}=3.6$ and $1.2 \mathrm{~Hz}, 3$-position $\mathrm{CH}$ of pyrrolyl), $6.77(1 \mathrm{H}$, $\mathrm{t}, J_{\mathrm{HH}}=1.2 \mathrm{~Hz}, 2$-position $\mathrm{CH}$ of pyrrolyl), 6.35, 6.30, 6.05 (each $1 \mathrm{H}$, each a t, Tp $\mathrm{CH} 4$ position), $6.09\left(1 \mathrm{H}, \mathrm{dd}, J_{\mathrm{HH}}=3.6\right.$ and $1.2 \mathrm{~Hz}, 3$-position $\mathrm{CH}$ of pyrrolyl), $2.50\left(3 \mathrm{H}, \mathrm{s}, \mathrm{NCCH}_{3}\right)$. ${ }^{13} \mathrm{C}\left\{{ }^{1} \mathrm{H}\right\}$ NMR $\left(\mathrm{CDCl}_{3}, \delta\right): 200.7(\mathrm{CO}), 172.5(\mathrm{Ru}-\mathrm{N}(\mathrm{H})=$ $C(\mathrm{Me})$ ), 144.6, 144.1, 140.7, 138.7, 135.9, 135.7, 134.5 (Tp 3 and 5 position and pyrrolyl 2-position with one overlap), 115.0, 110.8 (3-position of pyrrolyl), 106.3, 105.5 ( $\mathrm{Tp} 4$ position, one overlap), $21.1\left(\mathrm{Ru}-\mathrm{N}(\mathrm{H})=\mathrm{CCH}_{3}\right)$. Anal. Calcd for $\mathrm{C}_{16} \mathrm{H}_{16} \mathrm{BN}_{7} \mathrm{O}_{2-}$ Ru: C, 42.77; H, 3.81; N, 24.94. Found: C, 43.28; H, 3.92; N, 24.50 .

TpRu(CO)( $\boldsymbol{N}$-pyrrolyl)(NCMe) (3). A THF solution of $\mathrm{TpRu}(\mathrm{CO})(\mathrm{NCMe})(\mathrm{OTf})(4)(0.394 \mathrm{~g}, 0.714 \mathrm{mmol})$ was cooled

(69) Arrowood, B. N.; Lail, M.; Gunnoe, T. B.; Boyle, P. D. Organometallics 2003, 22, 4692-4698. to $-78{ }^{\circ} \mathrm{C}$. A cooled $\left(-78{ }^{\circ} \mathrm{C}\right)$ solution of lithium $N$-pyrrolyl $(0.522 \mathrm{~g}, 0.714 \mathrm{mmol})$ in $\mathrm{THF}$ was slowly transferred by cannula into the solution containing 4 . The resulting mixture was allowed to warm to room temperature, and the solvent was removed under reduced pressure. The residuals were dissolved in minimal methylene chloride and were passed through a column of silica gel. A brown band was collected and reduced to $2 \mathrm{~mL}$ under vacuum. The addition of approximately $50 \mathrm{~mL}$ of hexanes resulted in the formation of a precipitate. The tan solid was collected via vacuum filtration and dried $(0.147 \mathrm{~g}, 46 \%)$. IR $(\mathrm{KBr}): v_{\mathrm{CO}}=1961 \mathrm{~cm}^{-1}, v_{\mathrm{CN}}=$ $2216 \mathrm{~cm}^{-1}, \nu_{\mathrm{BH}}=2490 \mathrm{~cm}^{-1} .{ }^{1} \mathrm{H} \mathrm{NMR}\left(\mathrm{CDCl}_{3}, \delta\right): 7.75,7.72$, $7.67,7.61,7.52,7.26$ (each $1 \mathrm{H}$, each a d, Tp $\mathrm{CH} 3$ or 5 position), $6.36\left(2 \mathrm{H}, \mathrm{t}, J_{\mathrm{HH}}=2.0 \mathrm{~Hz}, 2\right.$-position pyrrolyl $\left.\mathrm{CH}\right), 6.25(2 \mathrm{H}$, $\mathrm{m}$ (overlapping triplets), $\mathrm{Tp} \mathrm{CH} 4$ position), $6.16\left(2 \mathrm{H}, \mathrm{t}, J_{\mathrm{HH}}=\right.$ $2.0 \mathrm{~Hz}, 3$-position pyrrolyl $\mathrm{CH}), 6.13$ ( $1 \mathrm{H}, \mathrm{t}, \mathrm{Tp} \mathrm{CH} 4$ position), $2.39\left(3 \mathrm{H}, \mathrm{s}, \mathrm{NCCH}_{3}\right)$. Homonuclear decoupling study of 3: A screw cap NMR tube was charged with $\mathrm{TpRu}(\mathrm{CO})(N$-pyrrolyl)$(\mathrm{NCMe})(3)(0.026 \mathrm{~g}, 0.059 \mathrm{mmol})$ and $0.7 \mathrm{~mL}$ of $\mathrm{CDCl}_{3}$. The irradiation of the resonance at $6.36 \mathrm{ppm}$ produced a singlet at $6.16 \mathrm{ppm}$. Changes in coupling to other resonances (e.g., doublets due to the $\mathrm{Tp}$ ligand 3 and 5 positions) were not observed. These results confirm that the resonances at 6.36 and $6.16 \mathrm{ppm}$ are due to the $N$-pyrrolyl ligand. ${ }^{13} \mathrm{C}\left\{{ }^{1} \mathrm{H}\right\} \mathrm{NMR}$ $\left(\mathrm{CDCl}_{3}, \delta\right): 202.1(\mathrm{CO}), 145.2,143.5,142.2,135.6,135.5,134.6$ (Tp 3 or 5 position), 130.9 (2-position of pyrrolyl), 122.4 (NCMe), 106.2, 106.1, 105.7, 105.6 (Tp 4 position and 3-position of pyrrolyl), $4.5\left(\mathrm{NCCH}_{3}\right)$.

Reaction of $\mathrm{TpRu}(\mathrm{CO})(\mathrm{N}$-pyrrolyl)(NCMe) (3) with HCl. A screw cap NMR tube was charged with $3(0.017 \mathrm{~g}, 0.037$ mmol) and approximately $0.7 \mathrm{~mL}$ of $\mathrm{CDCl}_{3}$. A ${ }^{1} \mathrm{H}$ NMR spectrum was acquired. The solution was cooled to $-78{ }^{\circ} \mathrm{C}$, and $0.05 \mathrm{~mL}(0.2 \mathrm{mmol})$ of $\mathrm{HCl}$ (in dioxane) was added. The solution was allowed to slowly warm to room temperature. A ${ }^{1} \mathrm{H}$ NMR spectrum revealed new resonances consistent with formation of free pyrrole $(6.06$ and $6.65 \mathrm{ppm})$ and $\mathrm{TpRu}(\mathrm{CO})$ $(\mathrm{NCMe})(\mathrm{Cl})$.

TpRu(CO)(NCMe)(OTf) (4). The preparation of 4 by an alternative method and details of characterization have been previously reported. ${ }^{43}$ Two new methods for the preparation of 4 are disclosed. Method A: $\mathrm{TpRu}(\mathrm{CO})(\mathrm{NCMe})(\mathrm{Cl})(0.240 \mathrm{~g}$, $0.573 \mathrm{mmol})$ and $\operatorname{AgOTf}(0.147 \mathrm{~g}, 0.573 \mathrm{mmol})$ were placed in a $50 \mathrm{~mL}$ round-bottom flask and dissolved in THF. The solution was heated to reflux for $30 \mathrm{~min}$ with the observation of a white precipitate. Upon confirmation of reaction completion by IR, the volatiles were removed under reduced pressure. The residual material was taken up in $\mathrm{CH}_{2} \mathrm{Cl}_{2}$ and passed through a plug of Celite. Upon addition of hexanes to the filtrate, a yellow solid precipitated. The solid was collected by vacuum filtration and dried $(0.286 \mathrm{~g}, 90 \%)$. Method B: TpRu$(\mathrm{CO})(\mathrm{NCMe})(\mathrm{Me})(2.929 \mathrm{~g}, 7.35 \mathrm{mmol})$ was taken up in $50 \mathrm{~mL}$ of $\mathrm{CH}_{2} \mathrm{Cl}_{2}$ and cooled to $-78^{\circ} \mathrm{C}$. Triflic acid $(0.65 \mathrm{~mL}, 7.3 \mathrm{mmol})$ was added dropwise to the $\mathrm{TpRu}(\mathrm{CO})(\mathrm{NCMe})(\mathrm{Me})$ solution, yielding observable $\mathrm{CH}_{4}$ evolution and a dark yellow appearance. After evacuation of all volatiles the residual yellow solid was taken up in minimal $\mathrm{CH}_{2} \mathrm{Cl}_{2}$ and passed through a column of silica. The yellow eluent was collected and isolated by addition of hexanes and vacuum filtration. The yellow solid (3.240 $\mathrm{g}, 80 \%)$ was dried overnight under vacuum.

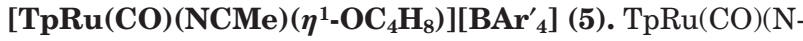
$\mathrm{CMe})(\mathrm{Cl})(0.095 \mathrm{~g}, 0.18 \mathrm{mmol})$ and $\mathrm{NaBAr}_{4}{ }_{4}(0.150 \mathrm{~g}, 0.179$ $\mathrm{mmol}$ ) were dissolved in $5 \mathrm{~mL}$ of THF and placed in a $50 \mathrm{~mL}$ reaction flask. The solution was heated to reflux for approximately $5 \mathrm{~min}$. The solution was cooled to room temperature, and the volatiles were removed under vacuum. The residuals were dissolved in $2 \mathrm{~mL}$ of methylene chloride and passed through a plug of Celite. The solvent was removed from the yellow filtrate under reduced pressure to leave an off-white solid. The product was washed with pentane and collected by vacuum filtration. The off-white product was dried in vacuo to yield $0.164 \mathrm{~g}(60 \%)$. IR $(\mathrm{KBr}): v_{\mathrm{CO}}=2004 \mathrm{~cm}^{-1}, v_{\mathrm{BH}}=2502$ 
$\mathrm{cm}^{-1} .{ }^{1} \mathrm{H} \mathrm{NMR}\left(\mathrm{CDCl}_{3}, \delta\right): 7.87,7.79,7.76,7.32$ (each $1 \mathrm{H}$, each a d, Tp CH 3 or 5 position), 7.69 (9H, m, overlap of $\mathrm{BAr}^{\prime}{ }_{4}$ ortho position and Tp 3 or 5 position), $7.54\left(5 \mathrm{H}, \mathrm{m}\right.$, overlap of $\mathrm{BAr}_{4}{ }_{4}$ para position and $\mathrm{Tp} \mathrm{CH} 3$ or 5 position), 6.41, 6.33, 6.21 (each $1 \mathrm{H}$, each a t, Tp $\mathrm{CH} 4$ position), $3.56\left(4 \mathrm{H}, \mathrm{m}, \mathrm{THF} \mathrm{CH}_{2}\right.$ 2-position), $2.34\left(3 \mathrm{H}, \mathrm{s}, \mathrm{NCCH}_{3}\right), 1.81\left(4 \mathrm{H}, \mathrm{m}, \mathrm{THF} \mathrm{CH}_{2}\right.$ 3-position. ${ }^{19} \mathrm{~F} \mathrm{NMR}\left(\mathrm{CDCl}_{3}, \delta\right):-62.7\left(\mathrm{BAr}_{4}^{\prime}\right) .{ }^{13} \mathrm{C}\left\{{ }^{1} \mathrm{H}\right\} \mathrm{NMR}$ $\left(\mathrm{CDCl}_{3}, \delta\right):{ }^{13} \mathrm{C}\left\{{ }^{1} \mathrm{H}\right\} \mathrm{NMR}\left(\mathrm{CDCl}_{3}, \delta\right): 198.6(\mathrm{CO}), 161.8\left(\mathrm{BAr}_{4}^{\prime}\right.$, ipso-carbon), 145.6, 144.9, 141.3, 137.8, 137.7, 136.6 (Tp 3,5

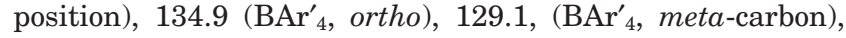
126.5 ( $N$-pyrrolyl, $\alpha$-position), 122.9 ( $N$-pyrrolyl, $\beta$-position), 117.7 (BAr' ${ }_{4}$, para-carbon), $108.0\left(\mathrm{NCCH}_{3}\right), 107.6,107.5,107.2$ (Tp 4 position), 76.0 (Bound THF, 1 and 2 position), 25.6 (bound THF, 3 and 4 position), $3.6\left(\mathrm{NCCH}_{3}\right)$. Anal. Calcd for $\mathrm{C}_{16} \mathrm{H}_{17} \mathrm{BN}_{8} \mathrm{ORu}: \mathrm{C}, 43.92 ; \mathrm{H}, 4.16 ; \mathrm{N}, 22.42$. Found: $\mathrm{C}, 43.58$; $\mathrm{H}, 3.98 ; \mathrm{N}, 21.82$.

Kinetic Studies: Formation of $\operatorname{TpRu}(\mathrm{CO})\left\{\kappa^{2}-N, N-(\mathrm{H})\right.$ $\left.\mathrm{N}=\mathrm{C}\left(\mathrm{CH}_{3}\right)\left(\mathrm{NC}_{4} \mathrm{H}_{3}\right)\right\}$ (2) from $\mathrm{TpRu}(\mathrm{CO})(\mathrm{NCMe})(\mathrm{Me})$ (1) and Pyrrole. Two reaction vessels were each charged with $\mathrm{TpRu}(\mathrm{CO})(\mathrm{NCMe})(\mathrm{Me})(\mathbf{1})(0.321 \mathrm{~g}, 0.806 \mathrm{mmol}, 0.161 \mathrm{M})$ and pyrrole $(5.0 \mathrm{~mL}, 0.072 \mathrm{~mol})$ to give homogeneous solutions. To one vessel, 30 equiv of NCMe (based on $\mathbf{1}$ ) was added. Both vessels were heated to $75{ }^{\circ} \mathrm{C}$ in an oil bath regulated by an IKA-Werke ETC1 temperature probe. Every $3 \mathrm{~h}$ the reaction solution was cooled for $15 \mathrm{~min}$ in an ice bath and an aliquot of $0.30 \mathrm{~mL}$ was taken. The aliquots were dried under vacuum, the residuals were taken up in $0.7 \mathrm{~mL}$ of $\mathrm{CDCl}_{3}$, and the resulting solutions were analyzed by ${ }^{1} \mathrm{H}$ NMR spectroscopy. This analysis was performed in triplicate to ensure reproducibility. Sample kinetic plots are given in the Supporting Information.

Kinetic Studies: Formation of $\operatorname{TpRu}(\mathrm{CO})\left\{\kappa^{2}-\boldsymbol{N}, \boldsymbol{N}-(\mathrm{H})\right.$ $\left.\mathbf{N}=\mathbf{C}\left(\mathrm{CH}_{3}\right)\left(\mathrm{NC}_{4} \mathrm{H}_{3}\right)\right\}$ (2) from $\mathbf{T p R u}(\mathrm{CO})(\mathrm{N}$-pyrrolyl)(NCMe) (3). A representative kinetic study is described. TpRu$(\mathrm{CO})(N$-pyrrolyl)(NCMe) (3) (0.019 g, $0.042 \mathrm{mmol})$ was dissolved in $0.7 \mathrm{~mL}$ of acetonitrile- $d_{3}$. The resulting yellow solution $(0.06$ $\mathrm{M})$ was placed in a screw cap NMR tube, and $15.4 \mu \mathrm{L}$ of pyrrole was added $(0.226 \mathrm{mmol})$. The solution was heated to $90^{\circ} \mathrm{C}$ in an oil bath. Periodically, the reaction vessel was removed from the oil bath and placed in an ice water bath for 15 min prior to analysis by ${ }^{1} \mathrm{H}$ NMR spectroscopy.

Preparation of $\boldsymbol{N}$ - $\boldsymbol{d}_{\mathbf{1}}$-Pyrrole. Pyrrole ( $5 \mathrm{~mL}$ ) was combined with approximately $80 \mathrm{~mL}$ of diethyl ether in a roundbottom flask. The solution was cooled to $-78{ }^{\circ} \mathrm{C}$, and $\mathrm{MeLi}$ (71.5 mmol) was added dropwise by syringe. The solution was allowed to warm to room temperature and the formation of a white precipitate was noted. The mixture was vacuum filtered, and the resulting solid was washed with diethyl ether. The solid was collected and combined with approximately $80 \mathrm{~mL}$ of diethyl ether. The slurry was cooled to $-78{ }^{\circ} \mathrm{C}$, and $\mathrm{D}_{2} \mathrm{O}$ (D, 99.9\%) (1.5 mL, $83 \mathrm{mmol})$ was added. The reaction was allowed to warm to room temperature to produce a yellow solution. The solution was vacuum filtered, and the volume of the filtrate was reduced to approximately $15 \mathrm{~mL}$. The organic layer was removed and stirred over $\mathrm{Na}_{2} \mathrm{SO}_{4}$ for $12 \mathrm{~h}$. The diethyl ether was removed by vacuum distillation. The product was collected by further vacuum distillation and analyzed by mass spectrometry and ${ }^{1} \mathrm{H}$ NMR spectroscopy for purity. Mass spectral data indicated a peak at $68 \mathrm{~m} / z$, and the ${ }^{1} \mathrm{H}$ NMR spectrum lacked the resonance due to the $\mathrm{N}-\mathrm{H}$ of pyrrole.

Reactions Using $\boldsymbol{N}$-Deuteriopyrrole and Perdeuteriopyrrole. The following procedures were used for all reactions involving deuterated pyrroles. A screw cap NMR tube was charged with $\mathrm{TpRu}(\mathrm{CO})(\mathrm{NCMe})(\mathrm{Me})(\mathbf{1})$ and the respective pyrrole. The tube was removed from the glovebox and heated in an oil bath at $90{ }^{\circ} \mathrm{C}$ for $6 \mathrm{~h}$. Before and after heating the reaction, the solution and headspace were analyzed using GCMS.

Computational Methods. Quantum calculations were carried out using the Gaussian 98 package. $^{70}$ The B3LYP hybrid functional was employed for all calculations. ${ }^{71}$ Heavy atoms were described with the Stevens relativistic effective core potentials (ECPs) and valence basis sets (VBSs). ${ }^{72}$ The valence basis sets of main group elements were augmented with a d polarization function. This ECP/VBS combination, termed SBK(d), has been validated for the calculation of a wide variety of transition metal properties in previous studies. ${ }^{39,40}$ As a model of the full (tris-pyrazolyl)borate (Tp) ligand, the tris(azo)borate (Tab) ligand, $\left[\mathrm{HB}(-\mathrm{N}=\mathrm{NH})_{3}\right]^{-}$, was used. In previous research, Tab was shown to faithfully reproduce the structure and energetics of the full Tp models for $\mathrm{C}-\mathrm{H}$ activation potential energy surfaces. ${ }^{39,63}$

All stationary points were fully optimized without symmetry constraint. Several conformations of the different ligands were investigated by torsion about the appropriate metal-ligand bond lengths; the lowest energy conformers found were used in the analyses given below. The energy Hessian was calculated at all stationary points to characterize them as minima (no imaginary frequencies) or transition states (one and only one imaginary frequency). The quoted energies include zeropoint, enthalpy, and entropic corrections determined from unscaled vibrational frequencies calculated at the B3LYP/ $\mathrm{SBK}(\mathrm{d})$ level of theory. All energetic determinations were done at $298.15 \mathrm{~K}$ and $1 \mathrm{~atm}$.

Acknowledgment. T.R.C. acknowledges support by the Office of Basic Energy Sciences, United States Department of Energy, for support of this research through Grant No. DE-FG02-03ER15387. A portion of these calculations was performed on the UNT computational chemistry resource, for which T.R.C. acknowledges the NSF for support through grant CHE-0342824. T.B.G. acknowledges support by the Office of Basic Energy Sciences, United States Department of Energy, for support of this research through Grant No. DEFG02-03ER15490 and the Alfred P. Sloan Foundation for financial support through a Research Fellowship. Mass spectra were obtained at the NCSU Department of Chemistry Mass Spectrometry Facility. Partial funding for the facility was obtained from the North Carolina Biotechnology Center and the National Science Foundation.

Supporting Information Available: Full details of computational studies and details of X-ray data collection and structure solution for complexes 2 and $3,{ }^{1} \mathrm{H}$ NMR spectrum of complex 3, sample kinetic plots, and full reference 70 . This material is available free of charge via the Internet at http://pubs.acs.org.

\section{OM0506668}

(70) Frisch, M. J.; et al. (see Supporting Information for full reference) Gaussian 98, Revision A.9; Pittsburgh, PA, 1998.

(71) Becke, A. D. J. Chem. Phys. 1993, 98, 5648-5652.

(72) Stevens, W. J.; Krauss, M.; Basch, H.; Jasien, P. G. Can. J. Chem. 1992, 70, 612-613. 